\title{
Competition in Public School Districts: Charter School Entry, Student Sorting, and School Input Determination
}

\author{
Nirav Mehta* \\ Western University \\ nirav.mehta@uwo.ca
}

June 14, 2012

\begin{abstract}
I develop a model of competition between charter schools and traditional public schools and estimate the model using administrative data from North Carolina. I use the model to quantify how existing charter schools have affected test scores for both charter and public school students and simulate charter school entry and student test scores were binding caps on charters lifted. I find that i) the mean effect of charter schools on attendant students (direct effect) is $25 \%$ of a standard deviation, ii) there is substantial heterogeneity in the mean direct effect by market, iii) the mean spillover effect on public school students is marginal, and iv) lifting caps on charter schools would more than double entry and cause increases in mean test scores similar to those under the capped scenario.
\end{abstract}

Key words: School choice, Charter schools, Education, Structural estimation, General equilibrium, Public economics

JEL codes: D58, I20, I28, H41, H72, L30

${ }^{*}$ I am grateful to my advisor, Kenneth Wolpin, and my committee members, Hanming Fang and Elena Krasnokutskaya, for their guidance, support, and time. The data were prepared and provided by Clara Muschkin and Kara Bonneau from the North Carolina Education Research Data Center. I have greatly benefited from discussions with Andrew Clausen, Flavio Cunha, Andrew Griffen, Eleanor Harvill, Lance Lochner, Rachel Margolis, Salvador Navarro, Áureo de Paula, Seth Richards, Shalini Roy, David Russo, Holger Sieg, Panos Stavrinides, Todd Stinebrickner, Michela Tincani, and Petra Todd. I also thank participants of the UPenn Empirical Micro lunch group and the Empirical Micro Seminar. The research reported here was supported by the Institute of Education Sciences, U.S. Department of Education, through Grant R305C050041-05 to the University of Pennsylvania. The opinions expressed are those of the author and do not represent views of the U.S. Department of Education 


\section{Introduction}

The provision of school choice is often proposed as a way to improve educational outcomes for students in poorly performing public schools. ${ }^{1}$ Charter schools have been at the center of much of the recent debate and policy focus concerning school choice, such as President Obama's education reform initiative, Race to the Top, which rewards states that lift restrictions on charter school growth (White (2009))..$^{2,3}$

Nationally, there has been rapid growth in the number of charter schools since they first opened in Minnesota in 1991; in 2008 about 1 million students attended over 3,000 charter schools in 40 states. This growth has arguably been constrained by legislative caps on the statewide number of charter schools in two-thirds of the states with charters. Policymakers in North Carolina, where 30,000 students are enrolled in about 100 charter schools, are currently debating whether to increase or eliminate the statewide cap on the total number of charter schools, which has been binding since 2002 (Wilder (2010)). ${ }^{4}$ Policymakers would like to know how expanding the role charter schools play in the public education system would affect the distribution of student test scores. Charter school advocates argue that charter schools improve the performance of both students attending charters ("direct effect") and also have a positive effect on the performance of students attending competing public schools ("spillover effect").

This theoretical ambiguity highlights how difficult it is to determine how charter schools affect student outcomes. To begin with, previous research suggests that the direct and spillover effects of charter schools are heterogeneous. ${ }^{5}$ Therefore, estimates of either effect that are based on a subset of charter schools may not generalize to other existing charter schools, let alone those that would enter in the absence of entry caps. The problem is complicated even within a particular market. Public schools may behave differently in the presence of a charter school than they would have as monopolists, meaning that students

\footnotetext{
1 "School choice" is a collective term which refers to charter schools, magnet and alternative public schools, and private schools coupled with voucher schemes.

${ }^{2}$ Charter schools are publicly funded schools that compete with traditional public schools for students and which, like public schools, cannot selectively admit students. Charter schools typically have considerably more autonomy than public schools regarding personnel decisions, curricula, school hours, and pedagogical methods, but they often have lower per-pupil resources due to a lack of separate capital funding streams. All students have access to a public school, but not all students have access to charter schools because charter schools enter certain markets and not others.

${ }^{3}$ Although charter schools are technically a type of public school, I refer to them as "charter schools" and traditional public schools as "public schools" for brevity.

${ }^{4}$ In fact, the North Carolina state legislature voted to eliminate the statewide cap in June, 2011, though the measure may be overturned by the State Board of Education (Robertson (2011)).

${ }^{5}$ Authors have directly studied the heterogeneity of charter schools (Gleason et al. (2010)) and this heterogeneity in part may explain the mixed estimates of direct and spillover effects.
} 
attending them no longer serve as a suitable control group for students at the charter school, even in the case of random assignment. Equilibrium interactions between charter and public schools may bias estimates of the direct effect of charter school entry if not taken into account. Additionally, student sorting on ability creates an inferential problem if student ability affects both school choices and test scores. Estimates of the effects of charter schools on the test score distribution must take into account the non-random assignment of students to charter schools. ${ }^{6}$ Furthermore, if charter and public schools take into account the composition of students in their markets when making decisions, differences in these compositions make it difficult to generalize treatment effects from one market to another.

In this paper I develop and estimate a model of competition between charter and public schools to quantify how charter schools affect the distribution of student test scores. I endogenize three key variables: i) charter school entry decisions, ii) charter and public school inputs, and iii) student school choices. i) Charter school entry decisions determine which populations of students will be affected. This is vital when we consider how lifting caps on charter schools may affect the distribution of test scores because it tells us how many more would open and in which markets they would open, which is important if the effects of charter schools are heterogeneous across markets. ii) By endogenizing school inputs, I can predict what inputs for public schools would have been in the absence of charters, which is necessary to quantify how charter schools have changed student performance relative to the monopoly scenario. In addition to quantifying how existing charter schools have affected the statewide distribution of test scores, endogenizing school effort choices allows me to quantify how lifting entry caps would further affect the distribution of test scores. iii) I model student school choices to capture the relationships between student ability, student school choices, and test scores. By modeling student school choices as a function of both student and school characteristics I can then naturally generalize estimates based on existing charter schools to charter schools that might enter in new markets were caps lifted. Both charter and public schools take student school choices into account when choosing inputs to test score production, which determine direct and spillover effects. The equilibrium framework I develop provides an internally consistent method to quantify both spillover effects and the bias introduced by ignoring equilibrium responses by public schools - indeed they are the same for a student with a given ability.

I fit the model to administrative data from the North Carolina public school system. The data are quite rich-they contain the universe of schools and students in the North Carolina public school system (including charter schools) from 1997 to 2005- and contain

\footnotetext{
${ }^{6}$ Even lottery-based charter school assignment schemes randomize among a group of students who applied to attend an oversubscribed charter school.
} 
variables that enable my estimation of the model's demand and supply sides. I observe public and charter school locations, charter school entry decisions, and detailed per-pupil school resources, which enter the model as a per-pupil capital index. School attendance, average weekly hours of homework reported done, and standardized test scores are recorded for each student in each year. Weekly hours of homework done comprise the second school input to test score production. The student-level data also contain student locations, which enter the model through the distance cost of attending a school and exogenously shift the probability a student will attend a charter school. I estimate the model using maximum likelihood, which fits observed patterns of charter school entry and continued operation, charter and public school effort choices, and student school choices and test scores.

Previous work on the effects of school choice programs typically adopts one of two strategies of addressing potential non-random student participation: 1) compare outcomes of applicants to oversubscribed programs who are randomized by lottery into the treatment (either public school choice program or charter schools) to those of applicants who are randomized out of the treatment; or 2) for charter schools, estimate student fixed effects using panel data to compare test score growth for students attending charter and public schools in markets with charters.

Hoxby and Rockoff (2004) and Angrist et al. (2010) find that charter school students who attend over-subscribed schools on average enjoy larger test score growth than students who were randomized to attend local public schools, but they note their results may not be generalizable to charter schools that are not in such high demand as to be oversubscribed. Cullen et al. (2006) study the effects of a Chicago public school choice program using an oversubscribed lottery randomization design and find that applicants randomized into the program fare no better on later standardized tests than those randomized out of the program. Both Cullen et al. (2006) and Angrist et al. (2010) note that their findings do not take into account potential equilibrium responses of public schools to the introduction of school choice programs, which I address in this paper.

Hanushek et al. (2007), Sass (2006), and Bifulco and Ladd (2006) estimate Value-Added models of test score growth using statewide student panel data for Texas, Florida, and North Carolina, respectively. ${ }^{7}$ All three find that the charter school dummy variable in a fixed-effect regression of student test score growth on school type has a negative sign, which authors interpret as a negative effect of charter schools on test score growth. ${ }^{8}$ Sass (2006) and Bifulco and Ladd (2006) also estimate the spillover effect of charter school entry by examining how

\footnotetext{
${ }^{7}$ I use the same dataset used by Bifulco and Ladd (2006).

${ }^{8}$ These results are not easily compared with lottery-based designs or this paper, which look at levels of test scores, not changes in growth rates of test scores.
} 
school fixed effects change in public schools close to and far from new charter schools, and find mixed results. ${ }^{9}$

This paper differs from most of the literature by modeling charter school entry and is the first to build and structurally estimate an equilibrium model of endogenous school inputs and student sorting. ${ }^{10}$ It also complements a related literature, where authors build and calibrate or estimate equilibrium models of competition between public and private schools. Epple and Romano (1998) develop and calibrate an equilibrium model of public and private school interactions to examine the effects of vouchers using aggregate data. Ferreyra (2007) builds on and structurally estimates Nechyba (2000)'s calibrated general equilibrium model of household sorting, public good provision, private schools, and housing prices in an equilibrium framework. The focus of these papers is on student sorting due to peer effects, the effectiveness of private school vouchers, and competition between public schools and private schools; none of them explore competition between public (or public and charter) schools, which they assume are monolithic and do not make input choices or any other decisions. ${ }^{11}$ School quality in these papers is a function of the average household income for students attending the school, as their focus is on residential location decisions and/or provision of public goods more than on school input provision and specific educational outcomes.

The model is structured as a sequence of one-period games played in each market and time period. ${ }^{12}$ There are three types of players in each period game: a measure of students, a public school, and a potential charter school entrant. In the Nash equilibrium in effort levels of the period game, even though neither charter nor public schools are allowed to explicitly admit the best students, they may be able to induce differences in the ability distributions of their students by choosing higher effort levels. Proponents of charter schools argue that such changes in effort levels are an important feature of competition between charter and public schools. ${ }^{13}$ Additionally, the model can accommodate either a positive or negative spillover effect of the presence of a charter school on the test scores of public school students.

\footnotetext{
${ }^{9}$ Imberman (2011) uses empty buildings per capita as instrument for charter school location and finds a negative spillover effect. Bettinger (2005) finds a negative direct effect and positive, yet imprecisely estimated, spillover effect of charter schools.

${ }^{10}$ Epple et al. (2011) have developed and are calibrating a model focusing on charter school location and input decisions without public school input choices for Washington DC. A working paper was not available when this manuscript was written.

${ }^{11}$ One exception is Chakrabarti (2008), where the author models competition between public schools and private voucher schools, and estimates implications of the model using a difference-and-differences approach.

${ }^{12} \mathrm{~A}$ market is the attendance zone for a public school, which captures the idea that students are typically assigned to attend a public school based on where they live.

${ }^{13}$ For example, Knowledge Is Power Program (KIPP) schools require parents to sign contracts to do homework with their children (KIPP (2010)).
} 
I estimate a mean direct effect of charter school entry of $25 \%$ of a standard deviation (sd) in test scores on students attending charter schools and a positive, though marginal spillover effect of $1.4 \%$ sd on public school students in those markets. I also find evidence of considerable heterogeneity by market in the direct effect of attending a charter school the 75 th percentile market average direct effect is twice that of the 25th percentile market. Moreover, I find evidence that the direct effect is a function of the measure of students who would attend the charter school, which cautions policymakers seeking to generalize results from oversubscribed charter schools if oversubscribed charters are, on average, more likely to have higher demand than charters at or below capacity. Simulations for the model in the absence of statewide caps on the number of charter schools during 2002-2005 (when in the data caps appear to have been binding) show that the number of charter schools in North Carolina would double in the absence of caps. Both average direct and spillover effects would be similar in new markets to what they were in markets entered while caps were binding.

\section{Model}

The model is a sequence of one-period games, each of which has three stages. First, the charter school decides whether to enter the market. If the charter school enters the market, the public school and the charter school simultaneously choose effort levels. Otherwise, the public school is a monopolist and chooses the monopolist level of effort. In the last stage, if the charter school has entered, students choose between schools. Otherwise, all students are assigned to the public school. The following exposition is for the period game, i.e. that played in one market and one time period, so I exclude market and time subscripts. Note that I use charter school "entry" to indicate entry or continued operation within a market. I discuss in Section 4.1 how consecutive periods within a market are linked together.

\section{$2.1 \quad$ Notation}

There is one public school in each market, denoted tps (for "traditional public school"). There is one potential charter school entrant in each market, denoted ch. Schools and student are indexed by $s$ and $i$, respectively. Variables in bold denote the pair of variables for both schools in a market, for example $\mathbf{k}=\left(k_{c h}, k_{t p s}\right)$ is the vector of school capital levels

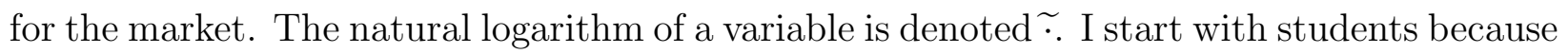
they take school actions as given and it is most natural to solve the game backwards. 


\subsection{Students}

There is a continuum of students of measure $\mu$ in the market. A student $i \in I$ has ability $a_{i}$, where $a_{i} \sim F\left(a_{i}\right)$ with density $f\left(a_{i}\right)$. Students have only one decision each period - they choose a school $s \in S_{i}$, their school choice set. If there is a charter school in student $i$ 's market then $S_{i}=\{t p s, c h\}$, otherwise $S_{i}=\{t p s\}$. Denote student $i$ 's school choice $s_{i}=c h$ if $i$ chooses to attend the charter school.

Students care about the test score they would receive at a school $s, y_{i s}$, and the nonpecuniary cost of attending a school $c_{i s} .{ }^{14}$ They also receive a choice-specific preference shock $\eta_{i s} \sim \mathrm{N}\left(0, \sigma_{\eta}^{2}\right)$. Student choice-specific utility is $u_{i s}=y_{i s}-c_{i s}+\eta_{i s}$.

Students take realized effort, $e_{s}^{o}$, and per-pupil capital, $k_{s}$ as given. ${ }^{15}$ The test score $y_{i s}$ is a function of ability $a_{i}$, school inputs $e_{s}^{o}$ and $k_{s}$, and a productivity shock $\nu_{i s}^{y}$, which is realized after the students choose schools

$$
y_{i s}=\underbrace{a_{i} \omega_{s}\left(\alpha_{s}\left(e_{s}^{o}\right)^{\beta_{s}}+\left(1-\alpha_{s}\right) k_{s}^{\beta_{s}}\right)^{\tau_{s} / \beta_{s}}}_{E y_{s}\left(e_{s}^{o}, a_{i}, k_{s}\right)}+\nu_{i s}^{y} \text {, }
$$

where $\nu_{i s}^{y} \sim$ i.i.d. $\mathrm{N}\left(0, \sigma_{\nu^{y}}^{2}\right)$ and $E y_{s}\left(e_{s}, a_{i}, k_{s}\right)$ is the deterministic portion of the test score given ability, school inputs, and school test score production function parameters. The first portion of the test score in equation (1) is a CES production function where ability is a student-specific Hicks-neutral productivity parameter and $\omega_{s}$ is a school-type Hicks-neutral productivity parameter. ${ }^{16}$ The parameter $\tau_{s}$ controls the degree of homogeneity, where $\tau_{s}=1$ indicates constant returns to scale and $\tau_{s}<1$ indicates decreasing returns to scale, and $\beta_{s}=1 /\left(1-\sigma_{s}\right)$, where $\sigma_{s}$ is the elasticity of substitution between $e_{s}^{o}$ and $k_{s}$. It will sometimes be convenient to write the test score as $y_{i s}=a_{i} E y_{s}\left(e_{s}^{o}, 1, k_{s}\right)+\nu_{i s}^{y}$.

Student $i$ 's cost of attending school $s$ depends on school effort, $e_{s}^{o}$, distance from the student to the school, $r_{i s}$, a fixed cost of attending the charter school, $c_{c h}$, and an abilityspecific cost of attending the charter school $c_{c h, a}$, according to ${ }^{17}$

$$
c_{i s}=c_{e} e_{s}^{o}+c_{r} r_{i s}+c_{c h} \mathbf{1}_{\{s=c h\}}+a_{i} c_{c h, a} \mathbf{1}_{\{s=c h\}}
$$

where $\mathbf{1}_{\{\cdot\}}$ is 1 if $\cdot$ is true and 0 otherwise. Denote $i$ 's optimal school choice policy $\gamma_{i}=$

\footnotetext{
${ }^{14}$ Neither traditional public schools nor charter schools may charge admission.

${ }^{15}$ I distinguish between "realized" or "observed" effort, $e_{s}^{o}$, and that chosen by the school, $e_{s}$, because there is a productivity shock on the chosen level of school effort. I show how this enters in the next subsection.

${ }^{16}$ As will be clear in Section 4.2.1 on identification of market ability distributions, the public school is without loss of generality normalized to have school Hicks-neutral productivity $\omega_{t p s}=1$.

${ }^{17}$ None of the parameters $c_{e}, c_{r}, c_{c h}$, or $c_{c h, a}$ are assumed to be "costs" in the estimation of the model in the sense that their signs are unrestricted.
} 
$\arg \max { }_{s \in S_{i}}\left\{u_{i s}\right\}$. Note that student utility satisfies the single-crossing property in ability: a high-ability student enjoys a larger increase in utility than a low-ability student from an increase in effort. This will affect school effort choices.

\subsection{Schools}

Each market is endowed with a public school, so public schools have no entry decision. Denote the charter school's entry decision $z \in Z=\{0,1\}$, where $z=1$ indicates entry. Each school is endowed with a capital level and location within the market, and the potential charter school entrant knows both schools' capital levels and locations before making its entry decision. If the charter school has entered the market, both types of schools make an effort decision, $e_{s}$. The school's cost of exerting effort allows for interactions between effort and both capital and school size

$$
c_{e s}=\psi_{s 1} e_{s}^{o}+\left(e_{s}^{o}\right)^{\psi_{s 2}}+\psi_{s 3} e_{s}^{o} \mu_{s}+\psi_{s 4} e_{s}^{o} k_{s}+\mathbf{1}_{\{s=c h\}} \psi_{\text {fr.Black }} \mu_{\text {Black }}
$$

where $\psi_{\text {fr.Black }}$ is the valuation of the charter school places on being located in a market with Black students and $\mu_{\text {Black }}$ is the share of Black students in the market. ${ }^{18}$ This last term allows the model to capture the fact that charter schools may want to serve Black students, which is sometimes explicitly part of their mission statements (Bifulco and Ladd (2007)). School size, $\mu_{s}$, enters the school objective with a coefficient of 1 , which means that the remaining school parameters are denominated in the school's size.

The school's objective is a weighted average of three elements: school size $\left(\mu_{s}\right)$, average test score of students at the school $\left(\bar{y}_{s}\right)$, and the cost of exerting the realized (i.e. observed) level of effort $\left(c_{e s}\right):^{19}$

$$
v_{s}\left(e_{s}, e_{-s} \mid \nu^{\mathbf{e}}\right)=\mu_{s}+\delta_{y s} \bar{y}_{s}-c_{e s},
$$

where $\nu^{\mathbf{e}}=\left(\nu_{c h}^{e}, \nu_{t p s}^{e}\right)$ is a pair of independently distributed effort productivity shocks that are realized after schools choose their effort levels. Each shock $\nu_{s}^{e}$ determines observed effort according to $e_{s}^{o}=e_{s} \nu_{s}^{e}$, where $\widetilde{\nu}_{s}^{e} \sim \mathrm{N}\left(0, \sigma_{\nu^{e}}^{2}\right)$. Although I suppress dependence on the them, the pairs of observed school efforts, $\mathbf{e}^{\mathbf{o}}$, effort productivity shocks, $\nu^{\mathbf{e}}$, and capital levels, $\mathbf{k}$, enter each school's objective because students take them into account when choosing schools - affecting the school's average test score and size. ${ }^{20}$

School incentives may be thought of from the perspective of the school principal - if no

\footnotetext{
${ }^{18}$ Note that the fraction of Black students in the market affects only the level of the charter school's equilibrium value of operating, not the optimal effort level once it has entered.

${ }^{19}$ I suppress the dependence of the cost function on school effort choices and the effort productivity shocks.

${ }^{20} \mathrm{I}$ also suppress the dependence of average test score and school size on $\left(\mathbf{e}^{\mathbf{o}}, \mathbf{k}\right)$ for notional ease.
} 
students attend the school she may be fired. A school's direct preferences for average test score $\delta_{y s}$ captures the idea that, in addition to caring about the size of their school, principals want the students to do well. If the average test score did not directly enter the school's objective function $\left(\delta_{y s}=0\right)$, the model would predict that monopoly public schools would exert no effort if the cost of effort is positive, because they would draw all students in their market and could avoid paying any effort exertion cost by doing so.

The charter school enters if and only if $\mathrm{E}_{\nu^{\mathbf{e}}}\left[v_{c h}^{*} \mid \nu^{\mathbf{e}}\right] \geq \underline{v}$, where $v_{c h}^{*}$ is the value of entry for the charter school in the entry subgame equilibrium, given a chosen effort pair (see Section 2.4 for equilibrium definition and derivation) and $\underline{v}$ is a random variable known to the charter school, which denotes an exogenous fixed cost of entry and operating. ${ }^{21}$

Because students in monopoly markets have no school choice, the average ability for students attending the monopoly public school is the market average, $\bar{a}$, and the measure of students attending is $\mu$, the market size: $v_{t p s}\left(e_{t p s} \mid \nu_{t p s}^{e}\right)^{\text {mono }}=\mu+\delta_{y, t p s} \bar{y}_{t p s}-c_{t p s}$.

If there is a charter school in the market, each school has a policy $\gamma_{s}=\arg \max { }_{e_{s}} \mathrm{E}_{\nu^{\mathbf{e}}}\left[v_{s}\left(e_{s}, e_{-s} \mid \nu^{\mathbf{e}}\right)\right]$, which says that each school chooses its own effort, $e_{s}$, to maximize its expected objective, given the action of the other school, $e_{-s}$ and the pair of effort productivity shocks, $\nu^{\mathbf{e}} \cdot{ }^{22}$ If there is only a public school it has a policy $\gamma_{t p s}^{\text {mono }}=\arg \max e_{e_{t p s}} \mathrm{E}_{\nu_{t p s}^{e}}\left[v_{t p s}^{\text {mono }}\left(e_{t p s} \mid \nu_{t p s}^{e}\right)\right]$.

\subsection{Equilibrium}

\subsubsection{Equilibrium Characterization}

I now show how I solve for the equilibrium of the period game after the entry decision. Figure 1 shows the timing of school decisions. The solution concept is subgame perfect Nash equilibrium, where the potential charter school entrant makes an entry decision in the first stage based on the expected payoff in the entry subgame. The Law of Large Numbers implies that the measure of students attending each school and school average test scores are known exactly, given productivity shocks $\nu^{\mathrm{e}}$.

Let $\mathcal{M}$ denote the set of measures of students, $\mathcal{F}_{a}$ denote the set of ability distributions, $\mathcal{R}$ denote the set of student distance distributions, $K$ be the set of school capital levels, $E$ the set of chosen effort levels for schools, $A$ denote the set of abilities, $R$ the set of student distances, $E^{o}$ denote the set of observed effort levels for schools, ETA be the set of preference shocks, and $S$ be the set of schools.

\footnotetext{
${ }^{21}$ The shock is drawn per market and time period, i.e. $\underline{v}_{t m}$.

${ }^{22}$ For estimation, to ease the computational burden I solve a slightly modified version of the school's problem where I do not integrate over the distribution of effort productivity shocks $\nu^{\mathbf{e}}$ in solving for effort and entry decisions. I have verified that the solutions to the school problems are similar with and without this integration. I could have instead allowed schools to condition on $\nu^{\mathbf{e}}$, but this would have significantly increased the burden of computing the likelihood.
} 
Figure 1: Extensive Form for Charter School Entry Decision and Subsequent School Effort Choice Subgame

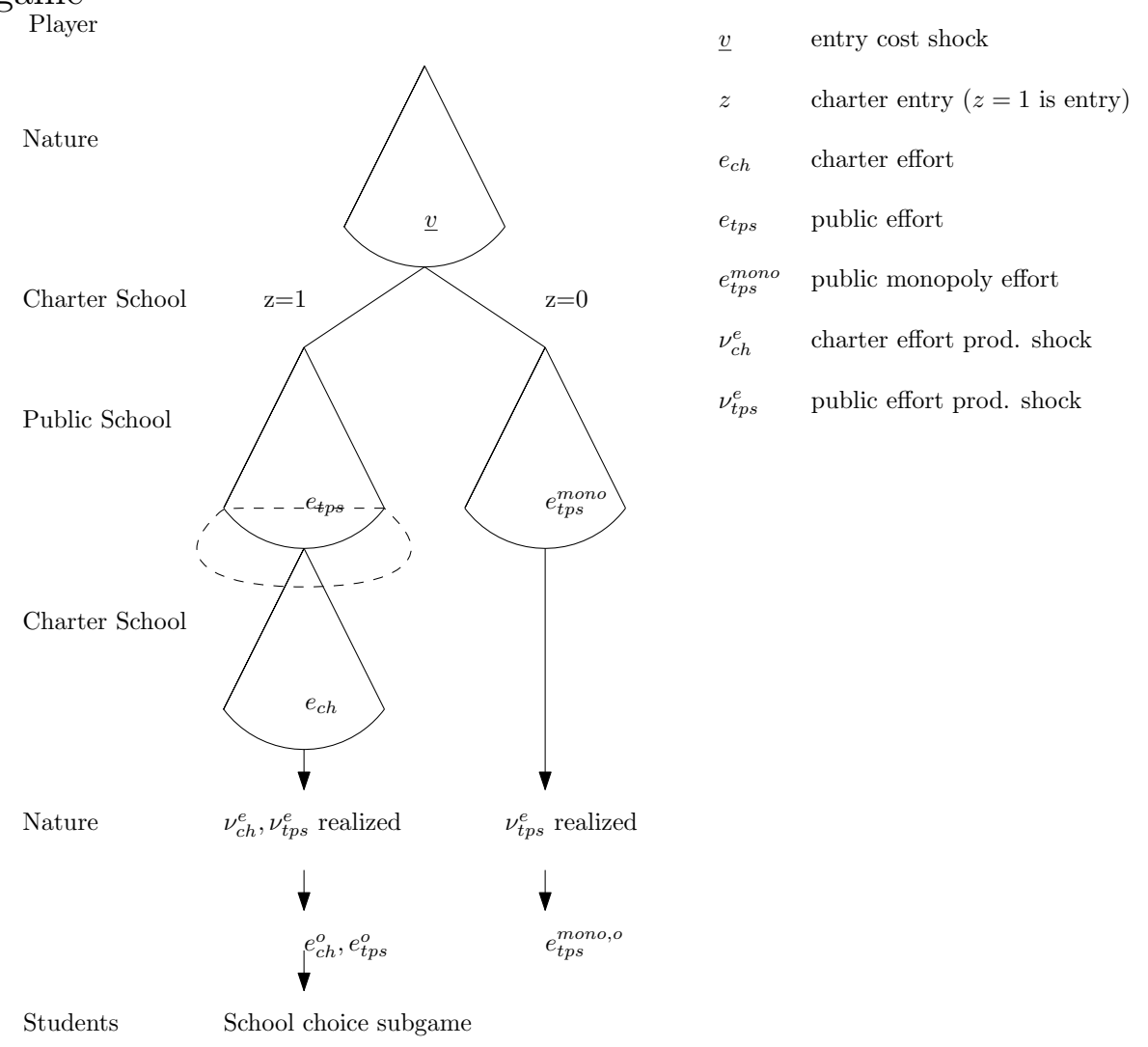

The strategies of students and schools in the entry subgame are

$$
\begin{array}{ll}
\text { Schools: } & \gamma_{s}: \mathcal{M} \times \mathcal{F}_{a} \times \mathcal{R}^{2} \times(K)^{2} \times E \mapsto E \\
\text { Students: } & \gamma_{i}: A \times R^{2} \times K^{2} \times\left(E^{o}\right)^{2} \times E T A^{2} \mapsto S
\end{array}
$$

Definition 1. An Entry Subgame Equilibrium is a vector of student choices $s_{i}^{*}$ and school effort levels $\mathbf{e}^{*}=\left(e_{c h}^{*}, e_{t p s}^{*}\right)$ such that

1. $s_{i}^{*}=\gamma_{i}\left(a_{i}, \mathbf{r}_{\mathbf{i}}, \mathbf{k},\left(\mathbf{e}^{\mathbf{o}}\right)^{*}, \eta_{\mathbf{i}}\right)$ maximizes student utility for students $i \in I$ and

2. $e_{s}^{*}=\gamma_{s}\left(\mu, F_{a}, \mathbf{R}, \mathbf{k}, e_{-s}^{*}\right)$ is the best response for schools $s \in\{t p s, c h\}$.

Proposition 1. Existence of Entry Subgame Equilibrium

Proof. See Appendix A.

Definition 2. A Monopoly Subgame Equilibrium is a vector of student choices $s_{i}^{* m o n o}$ and public school effort level $e_{t p s}^{* \text { mono }}$ such that

1. $s_{i}^{* \text { mono }}=$ tps for students $i \in I$ and 


$$
\text { 2. } e_{t p s}^{* m o n o}=\gamma_{t p s}^{\text {mono }}
$$

Definition 3. A subgame perfect Nash equilibrium for the period game is an entry decision $z^{*}$ and student and school decisions $\left(s_{i}^{*}, \mathbf{e}^{*}, s_{i}^{* m o n o}, e_{t p s}^{* \text { mono }}\right)$ such that

1. Given an entry cost shock $\underline{v}$ and entry subgame decisions $\left(s_{i}^{*}, \mathbf{e}^{*}\right), z^{*}=1$ if $\mathrm{E}_{\nu^{\mathbf{e}}}\left[v_{c h}^{*} \mid \nu^{\mathbf{e}}\right] \geq$ $\underline{v}$ and 0 otherwise,

2. for $z^{*}=1$, the subgame equilibrium is an Entry Subgame Equilibrium, and

3. for $z^{*}=0$, the subgame equilibrium is a Monopoly Subgame Equilibrium.

I solve the model by first computing the market equilibrium for the entry subgame and then comparing the equilibrium value to the charter school with its entry cost shock to determine the entry decision. In the subgame, I first solve for student demand as a function of school effort choices, given capital levels, ability, and distances both schools. Note that, because I need to know how far a student is from both schools to compute student school choice probabilities, I solve the model, given school effort choices, for students of each distance bin and then compute school size and average abilities at each school by summing over all bins in the market using the market distance distribution. I then plug the school size and average ability at each school into the school objectives (they enter through the measure of students attending each school $\mu_{s}$ and the average test scores at each school $\bar{y}_{s}$ ) and solve for the Nash equilibrium in school effort, given charter school entry.

A student with ability $a_{i}$ chooses a charter school if and only if

$$
\begin{gathered}
\mathrm{E}_{\nu^{y}}\left[y_{i, c h}\right]-c_{i, c h}+\eta_{i, c h} \geq \mathrm{E}_{\nu^{y}}\left[y_{i, t p s}\right]-c_{i, t p s}+\eta_{i, t p s} \\
\Leftrightarrow \\
a_{i} \underbrace{\left(E y_{c h}\left(e_{c h}, 1, k_{c h}\right)-c_{c h, a}-E y_{t p s}\left(e_{t p s}, 1, k_{t p s}\right)\right)}_{\Delta\left(x \beta_{x}\right)}+\underbrace{\left(\eta_{i, c h}-\eta_{i, t p s}\right)}_{\Delta \epsilon_{i}} \geq \underbrace{c_{e}\left(e_{c h}^{o}-e_{t p s}^{o}\right)}_{\Delta c_{e}}+\underbrace{c_{r}\left(r_{i, c h}-r_{i, t p s}\right)}_{\Delta c_{r i}}+\underbrace{c_{c h}}_{\Delta c_{c h}} \\
\Leftrightarrow \\
a_{i} \Delta\left(x \beta_{x}\right)+\Delta \epsilon_{i} \\
\geq \underbrace{\Delta c_{e}+\Delta c_{r i}+\Delta c_{c h}}_{\Delta c_{i}}
\end{gathered}
$$

where $\Delta \epsilon_{i} \sim \mathrm{N}\left(0, \sigma_{\Delta \epsilon}^{2}\right)$ and $\sigma_{\Delta \epsilon}^{2}=2 \sigma_{\eta}^{2}$. Equation (5) says that if the charter school has higher net effective school inputs, i.e. $\Delta(x \beta)>0$, higher ability students are more likely to attend it than low ability students because students of all abilities pay the same non-pecuniary cost of attending either school.

Because I assume ability is distributed normally within the market according to $F\left(a_{i}\right)=$ $\mathrm{N}\left(\bar{a}, \sigma_{a}^{2}\right)$, the left hand side of $(5)$ is the sum of two independent normals and is distributed 
according to

$$
a_{i} \Delta\left(x \beta_{x}\right)+\Delta \epsilon_{i} \sim \mathrm{N}\left(\bar{a} \Delta\left(x \beta_{x}\right), \sigma_{a}^{2} \Delta\left(x \beta_{x}\right)^{2}+\sigma_{\Delta \epsilon}^{2}\right) .
$$

This provides an analytical expression for the share of students attending the charter school, given a distance difference $\Delta c_{r i}, \mu_{r, c h}$ :

$$
\mu_{r, c h}\left(\Delta c_{r i}\right)=1-\Phi\left(\frac{\Delta c_{e}+\Delta c_{r i}+\Delta c_{c h}-\bar{a} \Delta\left(x \beta_{x}\right)}{\sqrt{\sigma_{a}^{2} \Delta\left(x \beta_{x}\right)^{2}+\sigma_{\Delta \epsilon}^{2}}}\right)
$$

where $\Phi$ denotes the standard cumulative normal distribution. ${ }^{23}$

There are $\rho \in 1, \ldots, R$ separate distance pairs in the market, each with a measure $\mu_{\rho}$. Therefore, the total measure of students at the charter school is the sum of the shares of students of each distance, weighted by the measure of students in each distance bin, $\mu_{\rho}$

$$
\mu_{c h}=\sum_{\rho=1}^{R} \mu_{\rho} \mu_{\rho, c h}\left(\Delta c_{\rho i}\right)
$$

A student with ability $a_{i}$ and relative charter distance cost $\Delta c_{r i}$ will choose the charter if and only if

$$
\Delta \epsilon_{i} \geq \Delta c_{i}-a_{i} \Delta\left(x_{t} \beta\right)
$$

which happens with probability $\Phi\left(\frac{a_{i} \Delta\left(x_{t} \beta\right)-\Delta c_{i}}{\sigma_{\Delta \epsilon}}\right)$. By Bayes' Rule, the average ability of student attending the charter school is

$$
\bar{a}_{r, c h}\left(\Delta c_{r i}\right)=\int_{a_{i}} a_{i} f_{r}\left(a_{i} \mid s_{i}=c h\right) d a_{i}
$$

where

$$
f_{r}\left(a_{i} \mid s_{i}=c h\right)=\frac{\Phi\left(\frac{a_{i} \Delta\left(x_{t} \beta\right)-\Delta c_{i}}{\sigma_{\Delta \epsilon}}\right) f\left(a_{i}\right)}{\mu_{r, c h}\left(\Delta c_{r i}\right)}
$$

is the density of the ability of students at the charter school, which takes into account their probability of selecting it. As with the measure of students attending the charter, the average ability of students attending the charter school is the weighted average of the average abilities of students attending the charter school from each bin:

$$
\bar{a}_{c h}=\sum_{\rho=1}^{R} \mu_{\rho} \mu_{\rho, c h} \bar{a}_{r, c h}\left(\Delta c_{r i}\right) / \sum_{\rho=1}^{R} \mu_{\rho} \mu_{\rho, c h} .
$$

\footnotetext{
${ }^{23}$ In estimation each market has a separate ability distribution, $F_{m}\left(a_{i}\right)$.
} 
I solve for $\mu_{t p s}$ and $\bar{a}_{t p s}$ analogously. After solving for $\bar{a}_{s}$, the average test score at school $s$ is $\bar{y}_{s}=\bar{a}_{s} \omega_{s}\left(\alpha_{s}\left(e_{s}^{o}\right)^{\beta_{s}}+\left(1-\alpha_{s}\right) k_{s}^{\beta_{s}}\right)^{\tau_{s} / \beta_{s}}=\bar{a}_{s} E y_{s}\left(e_{s}^{o}, 1, k_{s}\right)$, which, along with $\mu_{s}$, is substituted into school objectives when I solve for optimal effort levels.

I numerically solve for the entry subgame equilibrium by iterating the best response functions for charter and public schools. ${ }^{24}$ I cannot obtain an analytical expression for the equilibrium because I am integrating over the probability of charter school attendance for each student in (9). ${ }^{25}$ The assumption that there is only one potential charter school per market per time period eliminates multiple equilibria where more than one charter may open in a market in a period. Multiple equilibria of this type do not help explain variation in the data because the story is about public and charter school competition and the determinants of entry, not competition between charter schools. ${ }^{26} \mathrm{I}$ do not have a proof that the equilibrium in the entry subgame is unique but do not believe it poses a problem in the estimation. See Appendix B for a discussion of uniqueness.

\subsubsection{Properties of the Equilibrium}

Students with the same abilities and pairs of distances from the schools have the same probabilities of choosing the charter school. There are two benefits a school receives from increasing its own effort levels, given the other school's effort: there is a direct effect from the increase in the average test score from higher effort and an equilibrium effect of higher average ability at the school. As charter school effort increases from very low values, the gain from higher average ability outweighs diminishing marginal returns on effort in the test score production function. At higher values of effort, however, diminishing returns to additional increases in effort outweigh additional gains in mean ability because most of the high ability students already attend the charter school. Therefore, at higher charter school effort levels, the average test score at the charter school exhibits decreasing returns in effort. Effort choices between charter and public schools are neither strategic complements nor strategic substitutes (Bulow et al. (1985)) globally because the school best response functions are generally non-monotonic.

The entry subgame equilibrium allows for a negative or positive effect of charter school entry on student test scores. If the charter school is much more productive per unit of effort exerted than the public school, high ability students will attend it with very high probability.

\footnotetext{
${ }^{24}$ Solving the system of two first-order conditions (one for each school) gives the same answer.

${ }^{25}$ Even if I characterize the equilibrium with school first-order conditions I still need to integrate over probabilities computed from the normal CDF because the average test score interacts with the measure of students at each school.

${ }^{26}$ Most middle schools that compete with at least one charter school compete with exactly one charter school.
} 
Depending on the weights public schools place on test scores and effort exertion, relative to school size, a public school may not find it advantageous to try and retain these students but rather may decrease its equilibrium effort from the monopoly level and cater to students with below-average ability.

\subsection{Discussion of Modeling Assumptions}

In this section I discuss some of the modeling decisions regarding the model's primitives, test score production, and school objective functions.

\subsubsection{Primitives}

The model is structured as a sequence of one-period games, which precludes public schools from investing in capital to deter charter school entry. This assumption is not as restrictive as it may seem because individual schools have little control over per-pupil funding, which is determined by property tax rates at the district level in North Carolina. ${ }^{27}$

For tractability of both the student and school problems, I only allow one charter school entrant per market. This assumption is supported by observed competition patterns in the data. Please see Section 3.1 for details and discussion of how I construct markets.

\subsubsection{Test Score Production Function}

The test score production function captures the idea that unobservable student ability may play an important role in test score production and allows public and charter schools to differ in the productivity of their inputs. When combined with the student school decision, it allows students to sort on their own ability, given school inputs. This is the inferential problem typically addressed in the literature on the effectiveness of school inputs on student achievement. I address this problem by explicitly modeling student decisions, where students choose schools based on their own ability, distance from schools, school inputs, and preference shocks. Distance serves as a source of exogenous variation in the cost of attending a charter school, which provides an exclusion restriction for the probability a student will choose to attend the charter.

The test score production function implies that only the ability of a student, current inputs, and the current productivity shock (not the previous test score) determine the test score. This assumption not only makes the student problem easier to solve but, more importantly, makes the school's problem tractable, as otherwise I would have to record the entire

\footnotetext{
${ }^{27}$ Were schools able to invest in building a reputation, which entered household demand, there might be a role for preemptive investments by public schools. This is beyond the scope of this paper.
} 
distribution of previous test scores at the school and take it into account when considering the current effort choice. ${ }^{28} 29$ This gain in tractability is weighed against the cost of effectively assuming a Value-Added framework, where the lagged test score is restricted to not affect test score growth.

Both capital and effort inputs are assumed to be the same for all students at the same school. The assumption is innocuous for capital, because most school capital is applied fairly evenly to students at the schools. ${ }^{30}$ Even were they not I do not have data on capital expenditures within a school that would allow me to distinguish otherwise. By contrast, effort choices for individual students are observed. Assuming that there is only one effort level per school per year allows me to avoid solving for each student's effort choice. I lose information on the variation of effort at a school, which means that I may end up overestimating the variance of ability distributions.

I do not include peer effects through ability in the test score production function. A Hicks-neutral peer effect composed of average ability of attendant students would not even be identified at traditional public schools, as it would only scale mean ability for market-level ability distributions recovered in the estimation procedure. ${ }^{31}$

\subsubsection{School Objective Functions}

The effort productivity shock, $\nu_{s}^{e}$, makes the model estimable. A school chooses a schoolwide effort level but, being a reasonably large entity with several teachers, etc., the realized effort level may differ slightly from that chosen by the school in the beginning of the period.

\section{Data}

I use administrative panel data on schools and students panels in North Carolina to estimate the model. The data are taken from the universe of all public and charter schools, and were provided by the North Carolina Education Research Data Center, which collects and processes data on the North Carolina public school system from the North Carolina Department of Public Education and National Center for Education Statistics. ${ }^{32}$ The data contain variables necessary to estimate student-level test score production functions based

\footnotetext{
${ }^{28}$ I do not have to record the previous test score in the student's state.

${ }^{29}$ Although forward-looking behavior may be more realistic, estimates of the ability distribution and capital and effort effectiveness from test score production functions with student fixed effects do not qualitatively change when lagged test scores are included.

${ }^{30}$ Special education and gifted and talented student programs are notable exceptions. Charter schools tend to have much smaller fractions of both types of students.

${ }^{31}$ Proof available upon request.

${ }^{32}$ Website http://www . childandfamilypolicy.duke.edu/project_detail.php?id=35
} 
on school-level inputs, and include detailed panels on teachers, students, and schools in the North Carolina public school system, as well as data on charter schools. For teachers, the data contain years of experience and the school in which they work. For students, the data contain demographic characteristics, which school they attend, grade in school, standardized reading and math test scores for students in grades 3-8 and grade 10, self-reported weekly hours of homework done, and student household locations. I use school-level data to compute computers per pupil and district per-pupil revenues. ${ }^{33}$

\subsection{Definition of Markets}

In the model, markets partition the state of North Carolina. The schools within a student's market constitute that student's choice set. In order to estimate the model each student's school choice set must be defined. However, because North Carolina charter schools do not have geographic cut-offs for attendance, I know neither which public school a student would have attended had he not chosen the charter school, nor which charter school(s) a student observed in a public school could have chosen to attend. ${ }^{34}$ I address this problem by designating each charter school to be in the market of the public school closest in distance. ${ }^{35}$ Therefore every charter school competes with only one public school.

In theory, a public school could be competing with several charter schools, each of which in turn could be competing with several public schools. The former (one public school competing with several charters) would mean that a student's choice set could include more than two schools and would fundamentally change how I solve for student decisions in the model. ${ }^{36}$ Sometimes one public school is the closest public school for more than one charter, which would mean that students at these schools may be choosing from more than two schools (the middle school and more than one charter school). The four times this occurs in the estimation sample, I designate the charter school closer to the public school as the charter school competitor and drop the other charter.

\footnotetext{
${ }^{33}$ Charter schools are considered to be their own school districts in North Carolina.

${ }^{34}$ I could use elementary school attendance to see which middle schools compete with charters by taking elementary schools which send students to charters, and seeing which public middle schools those elementary schools also send students to. However, more than half of charter school students in my data are never in public schools, so it is difficult to say which public middle school they would have gone to based on their elementary school attendance.

${ }^{35}$ I found the neighbors using the STATA module GEONEAR (Picard (2010)). The module gives the closest geodesic distance school for each charter school. Five charter schools were missing latitude and longitude, so I looked them up manually using their addresses from the NCES (NCES (1998)) and Google Earth (Google (2010)).

${ }^{36}$ There is a simple expression for the probability that a student of a certain ability will choose the charter school when there are two schools in the student's choice set, which I use then solving for school best responses. I could use a multinomial logit, but I would then have to expend more resources to solve for school best responses when estimating the model.
} 
I chose this method based on geographical restrictions because it provides a consistent definition of markets. It is tempting to create markets based on observed competition patterns. For example, if a charter school has many students in attendance who transferred from two nearby public schools, one might combine the two public schools in one market. However, this method poses a problem in counterfactual scenarios because it does not tell me how to combine public schools in areas where there are no charter schools, which is necessary in order to compute charter school entry probabilities for all markets.

\subsection{Estimation Sample}

Although the NCERDC data contain information on elementary, middle, and high schools for the years 1995-2006, I restrict my analysis to middle schools, which includes grades 6-8. There are three reasons for focusing on middle schools: 1) the three school types may have different test score production functions, 2) I only observe standardized test scores for the 10th grade for high school students and 3) middle school provides a natural decision-point for students because most students switch schools between grades 5 and 6 . I restrict my analysis to the years 1998-2001 because 1998 is the first year charter schools were allowed in North Carolina, and the 100-school cap on charter schools was clearly not binding in 2001 (it comes close to binding in 2002 and 2003). ${ }^{37}$ This way I avoid having to model the interdependence of charter school entry decisions that would be induced by the cap.

The NCERDC data contain 1,128,935 observations (student-year) for students in public schools and 10,165 observations for students in charter schools in grades 6-8 during the years 1998-2001. I exclude markets where public schools (and the associated charter schools) open or close during the observation period (leaving me with 1,007,917 and 7,594 public and charter school students, respectively). ${ }^{38}$ This restricts the initial sample of 2,703 public school observations and 126 charter school observations with at least one grade in the grades 6-8 to 2,366 public school observations and 108 charter school observations, after removing charter schools associated with new or dead markets. I also removed public schools that had no children attending, after removing children from the sample as detailed above in the student sample restrictions. I also exclude students who are observed attending public schools outside their designated market (leaving me with 1,005,966 public and 5,574 charter school students). ${ }^{39}$ I further exclude students observed for only one year, or observed attending

\footnotetext{
${ }^{37}$ This is only for the likelihood for school and student outcomes. As I discuss in Section 4.2.1, I also use data for the year 1997 to identify market ability distributions.

${ }^{38}$ I do this so markets remain stable during the observation period.

${ }^{39}$ Students who attend charter schools outside their markets have on average lower test scores and are more likely to be Black. Please see Appendix F for more details on sample selection and for a calculation of the bias the sample restrictions may introduce when I calculate the direct treatment effect.
} 
more than 2 schools in the 3 years of middle school because the latter students are moving, which is also not part of the student's choice set (leaving me with 956,509 public school and 5,073 charter school students). After I exclude students missing standardized test scores, the estimation sample includes 912,748 observations for public school students and 4,911 observations for students in charter schools. This is associated with $81 \%$ of public school observations and $48 \%$ of charter school observations from the initial sample. Finally, due to the large number of student-year observations, I estimate the model on a random subsample of students in markets that have never had charter schools, leaving me with a final estimation sample of 78,294 observations in markets without charter schools, 63,216 observations of students in public schools in markets with charter schools, and 4,911 observations of students in charter schools over the years 1998 to 2001. ${ }^{40}$ The final estimation sample contains 496 public school markets per year over the period 1998-2001. ${ }^{41}$

\subsection{Test Scores, Capital, and Effort}

The NCERDC data contain standardized reading and math test scores for grades 6-8. ${ }^{42}$ The test score used in the model is the average of the reading and math test scores, which is then normalized to have mean 3 and standard deviation 1 by grade so they are comparable across grades. ${ }^{43,44}$

School inputs used for the per-pupil capital index are computers per pupil, teachers per pupil, and fraction of teachers at a school with high experience (4 or more years). I treat experience in this way based on Rivkin et al. (2005), which argues that after the first three years of experience, later years of teacher experience have little, if any, effect on student achievement. ${ }^{45}$ I combine these into a per-pupil index. ${ }^{46}$ Capital is a per-pupil measure so

\footnotetext{
${ }^{40}$ The sample is $100 \%$ of students in markets with fewer than 100 students, $20 \%$ of students in markets with at least 100 and fewer than 200 students, $15 \%$ of students in markets with at least 200 and fewer than 300 students, $10 \%$ of students in markets with at least 300 and fewer than 400 students, and $5 \%$ of students in markets with 400 or more students.

${ }^{41}$ There were not enough students at some schools to calculate mean effort, which is required of both public and charter schools to calculate student school choices, leaving 98 charter and public schools in entry markets for estimation.

${ }^{42}$ The tests are vertically scaled, which means that students in the 7th grade have average test scores that are higher than the average of those in the 6th grade and lower than the average for those in the 8th grade.

${ }^{43}$ The estimation sample has a mean test score of 3.05, since some observations are lost while making sample restrictions. The standard deviation of the test score in the estimation sample is 0.95 .

${ }^{44}$ I set the average test score to 3 to ensure that all markets have ability distributions with positive means, otherwise the model would predict that effort for any school in such a market would be zero if schools face positive effort costs.

${ }^{45}$ Wiswall (2011) finds evidence that teacher quality does improve in later years, using a less restrictive framework. I maintain my assumption for simplicity.

${ }^{46}$ The details of how I construct the index are in Appendix C.
} 
there are no capital scale effects. ${ }^{47}$

A school makes its decisions knowing the per-pupil level of capital it would receive. The measure of capital used in estimation is a predicted value based on per-pupil revenue and school type (please see Appendix $\mathrm{C}$ for details). I treat per-pupil capital in this manner because I need to know what it would have been for charter schools in markets charters have not entered, where computers, teachers, and experienced teachers per pupil are not observed. By using the predicted per-pupil capital levels as inputs for both types of schools, I treat per-pupil capital for public and charter schools similarly.

I measure student effort with self-reported data on the hours of homework students say they typically do per week. I then average these data within each school-year, to create a school-wide effort variable per school-year. ${ }^{48}$ This is meant to capture broad differences in workloads between charter schools and public schools.

\subsection{Distance Between Students and Schools}

The distance between a student and each school in its choice set plays an important role in identification of the test score production function parameters because it shifts the probability a student will attend the charter school without directly affecting the test score (unlike student ability). Moreover, each school takes into account the distance distribution (that is, the fraction of students that are $r_{c h} \mathrm{~km}$ away from the charter school and $r_{t p s} \mathrm{~km}$ from the public school) of students in the market when choosing its effort level, and the charter school takes it into account when making its entry decision. I convert both student and school latitude and longitude into geodesic distances using the Stata module VICENTY (Nichols (2003).)

Because I need a distance distribution for every market, including markets where I never observe charter school entry and therefore lack data on student distances from charter schools, I discretize the distance distribution for each market and model the relationship between the distance distribution for public schools and charter schools, assuming that public school, charter schools, and students are all endowed with locations within markets, and that all locations are observed by both types of schools and students (the details of the discretization are in Appendix D.) This market distance distribution, in addition to closing the model from the school's perspective, also allows me to deal with missing student distances, which is of particular importance for students who only ever attend charter schools because charter schools typically do not report locations for their students. ${ }^{49}$ If I observe a student's

\footnotetext{
${ }^{47}$ State funding is also per-pupil in North Carolina.

${ }^{48}$ Recall that effort in my model is a school-wide, not individual, choice.

${ }^{49}$ Telephone conversations with NCDPI indicate that charter schools often fill in less paperwork because
} 
location at least once and it is missing in another year I assume the student did not move and assign it the previous location, so long as it attends a school in the same city as before.

\subsection{Facts about Charter Schools in North Carolina}

Table 1 shows the descriptive statistics for capital and effort by market and school type. Charter schools also have about three-quarters of the per-pupil capital levels of public schools ( 0.43 versus 0.54 and 0.56 for monopolist and competitor public schools, respectively), while effort is significantly higher for both charter and public schools in entry markets than it is for public schools in non-entry markets. Charter schools are much more likely to stay in a market once they have entered it (probability of entry given entry last period is 95.29\%), and unlikely to enter markets they have not previously entered (probability of entry given no entry last period is $2.57 \%$ ). Almost two-thirds of markets that have a charter school this period had one last period. Charter schools in North Carolina are much smaller than public schools, on average comprising $9 \%$ of a market.

Table 1: Descriptive Statistics for Capital and Effort, by Market and School Type

\begin{tabular}{lrlrrrrr} 
& \multicolumn{3}{c}{ Capital } & \multicolumn{3}{c}{ Effort } \\
Entry & Mean & SD & N & Mean & SD & \multicolumn{1}{c}{ N } \\
\hline Charter & 0.43 & 0.03 & 98 & 2.66 & 0.95 & 98 \\
Public & 0.56 & 0.02 & 98 & 2.69 & 0.62 & 98 \\
\hline No Entry & & & & & & \\
\hline Public & 0.54 & 0.02 & 1652 & 2.43 & 0.50 & 1652
\end{tabular}

The following facts show patterns for charter school entry, endogenous school effort, and student outcomes. First, charter schools enter larger markets and markets in which where they would have more resources (Table 2). Second, the amount of time spent doing homework is higher in markets in charters (Table 3). Third, student choices suggest sorting on ability. In the year before a charter school enters a market, students who attend charters in the following year have $5 \%$ of a standard deviation higher test scores than those who do not attend the charter in the following year. Finally, students in charter schools have the highest test scores, followed by students in public schools in markets charters have entered, followed by students in public schools in markets without charters (Table 4). ${ }^{50}$

they are understaffed relative to public schools.

${ }^{50}$ Please see Appendix F for a discussion of how sample selection affects test score distributions. 
Table 2: Charter School Entry Patterns by Market Characteristics

\begin{tabular}{lc} 
All markets & 0.056 \\
Charter per-pupil capital & \\
\hline above median $k_{c h}$ & 0.095 \\
below median $k_{c h}$ & 0.017 \\
Market size & \\
\hline above median $\mu$ & 0.067 \\
below median $\mu$ & 0.045
\end{tabular}

Table 3: Average Hours of Homework

\begin{tabular}{lcc} 
& No Charter in Market & Charter in Market \\
\hline Public School & $2.43^{*}$ hours & 2.69 hours \\
Charter School & - & 2.66 hours \\
\hline${ }^{*}$ Monopoly average hours are different from those of public \\
and charter schools in entry markets (p-value $<0.001$ )
\end{tabular}

Table 4: Average Test Scores of Students by School Type

\begin{tabular}{lcc} 
& No Charter in Market & Charter in Market \\
\hline Public School & $3.028^{*}$ & $3.075^{*}$ \\
Charter School & - & $3.137^{*}$ \\
\hline
\end{tabular}

* All means are significantly different from each other (pair-wise t-tests, p-value $<0.0001$ ) 


\section{Estimation}

\subsection{Likelihood}

The one-period game is played in every market $m \in 1, \ldots, M$ and time period $t \in 1, \ldots, T$. In every time period there is a new measure of students with abilities and locations within the market and a new public school and potential charter school entrant with exogenous per-pupil capital levels and locations within the market. The only links between two periods in the same market are the ability distribution, which is unchanged within a market over time, and whether a charter entered in the previous period in the market, which affects the entry cost shock distribution. Refer to the extensive form of the period game in Figure 1 for timing details within a period.

The likelihood includes probability (or likelihood) statements for charter school entry decisions, school effort levels, student school choices, and student test scores. I assume that entry cost shocks $\underline{v}_{t m}$, effort productivity shocks $\nu_{s t m}^{e}$, test score productivity shocks $\nu_{i s t m}^{y}$, and preference shocks $\eta_{i s t m}$ are independently distributed.

\subsubsection{School Contribution to Likelihood}

The potential charter school entrant in each market compares the expected value of entry $\mathrm{E}_{\nu^{\mathbf{e}}}\left[v_{c h, t m}^{*}\right]$, which is a function of market size $\mu_{t m}$, distance distribution $\mathbf{R}_{\mathbf{t m}}$, school capital levels $\mathbf{k}_{\mathbf{t m}}$ and the market ability distribution $F_{m}\left(a_{i}\right)$, with the period-specific entry cost

shock $\underline{v}_{\text {entry }}$. In the first period of the model, or if the potential charter school entrant did not enter in the market in the previous period, there was no prior observed entry $\left(z_{t-1, m}^{o}=0\right)$. The potential charter school entrant enters $\left(z_{t m}=1\right)$ with probability

$$
\operatorname{Pr}\left\{z_{t m}=1 \mid z_{t-1, m}^{o}=0\right\}=\Phi\left(\frac{\mathrm{E}_{\nu^{\mathbf{e}}}\left[v_{c h, t m}^{*}\right]-\mu_{\underline{v}}}{\sigma_{\underline{v}}}\right) .
$$

The potential charter school entrant in a market where there was previously a charter school entrant solves a similar problem, but the entry cost shock is drawn from a different distribution. Note that the assumption is that a different potential entrant makes an entry decision in each year - the previous entrant's decision enters only through the parameters of the entry cost shock distribution. Its probability of entry is

$$
\operatorname{Pr}\left\{z_{t m}=1 \mid z_{t-1, m}^{o}=1\right\}=\Phi\left(\frac{\mathrm{E}_{\nu^{\mathbf{e}}}\left[v_{c h, t m}^{*}\right]-\mu_{\underline{v}, \text { given entry }}}{\sigma_{\underline{v}_{\text {given entry }}}}\right)
$$

The likelihood of the observed effort in markets where charter schools have entered is 
simply the density of the difference between effort predicted by the model (i.e., that chosen in equilibrium by each school) and the observed effort (i.e., chosen effort augmented by the effort productivity shock):

$$
L\left\{e_{s t m}^{o} \mid z_{t m}^{o}=1\right\}=\frac{1}{\sigma_{\nu_{s}^{e}}} \phi\left(\frac{\tilde{e}_{s t m}^{o}-\tilde{e}_{s t m}^{*}}{\sigma_{\nu_{s}^{e}}}\right)
$$

where . denotes the natural logarithm of a variable and $e_{\text {stm }}^{*}$ is the duopoly equilibrium effort level. The likelihood of the observed monopoly effort level is similar:

$$
L\left\{e_{t p s, t m}^{o} \mid z_{t m}^{o}=0\right\}=\frac{1}{\sigma_{\nu_{t p s}^{e}}^{e}} \phi\left(\frac{\tilde{e}_{t p s, t m}^{o}-\tilde{e}_{t p s, t m}^{* \text { monoly }}}{\sigma_{\nu_{t p s}^{e}}^{e}}\right)
$$

\subsubsection{Student Contribution to Likelihood}

Student likelihood statements are all conditional on ability $a_{i}$, which is integrated out in the likelihood function according to the market ability distribution.

The probability student $i$ with ability $a_{i}$ attends the charter school $\left(s_{i t m}=c h\right)$ is a function of observed school inputs $\left(\mathbf{k}_{\mathbf{t m}}, \mathbf{e}_{\mathbf{t m}}^{\mathbf{o}}\right)$, which enter $\Delta\left(x_{t m} \beta_{x}\right)$, and the pair of distances from the student to both schools $\mathbf{r}_{\mathbf{i t m}}$, which enter $\Delta c_{i t m}$, and own ability $a_{i}{ }^{51}$

$$
\operatorname{Pr}\left\{s_{i t m}=c h \mid z_{t m}^{o}=1, a_{i}\right\}=\Phi\left(\frac{a_{i} \Delta\left(x_{t m} \beta_{x}\right)-\Delta c_{i t m}}{\sigma_{\Delta \epsilon}}\right) .
$$

The observed test score $y_{i s t m}^{o}$ is a function of ability $a_{i}$, school inputs $e_{\text {stm }}^{o}$ and $k_{\text {stm }}$, and a productivity shock $\nu_{i s t m}^{y}$. From the test score production function, the distribution of the observed test score of a student with ability $a_{i}$ attending the charter school is $y_{i, c h, t m}^{o} \sim$ $\mathrm{N}\left(E y_{c h}\left(e_{c h, t m}^{o}, a_{i}, k_{c h, t m}\right), \sigma_{\nu^{y}}^{2}\right)$, which results in a likelihood of observed charter school test score of

$$
L\left\{y_{i, c h, t m}^{o} \mid z_{t m}^{o}=1, s_{i t m}^{o}=c h, a_{i}\right\}=\frac{1}{\sigma_{\nu^{y}}} \phi\left(\frac{y_{i, c h, t m}^{o}-E y_{c h}\left(e_{c h, t, m}^{o}, a_{i}, k_{c h, t, m}\right)}{\sigma_{\nu^{y}}}\right) .
$$

The test score for a student attending the public school in a market with charter school entry uses the public school's production function and inputs:

$$
L\left\{y_{i, t p s, t m}^{o} \mid z_{t m}^{o}=1, s_{i t m}^{o}=t p s, a_{i}\right\}=\frac{1}{\sigma_{\nu^{y}}} \phi\left(\frac{y_{i, t p s, t m}^{o}-E y_{t p s}\left(e_{t p s, t, m}^{o}, a_{i}, k_{t p s, t, m}\right)}{\sigma_{\nu^{y}}}\right),
$$

\footnotetext{
${ }^{51}$ This was derived in equation (5), but now $\Delta(x \beta)$ has market and time subscripts, $\Delta\left(x_{t m} \beta_{x}\right)$.
} 
as does the test score for a student attending a monopolist public school:

$$
L\left\{y_{i, t p s, t m}^{o} \mid z_{t m}^{o}=0, s_{i t m}^{o}=t p s, a_{i}\right\}=\frac{1}{\sigma_{\nu^{y}}} \phi\left(\frac{y_{i, t p s, t m}^{o}-E y_{t p s}\left(e_{t p s, t, m}^{m o n}, a_{i}, k_{t p s, t, m}\right)}{\sigma_{\nu^{y}}}\right) .
$$

The likelihood function combines the previous probability and likelihood statements for markets and students and integrates over the ability distribution in a market, given all the data $X$ and parameters $\theta$ ( $X$ and $\theta$ are suppressed in the right-hand-side):

$$
\begin{aligned}
& L(\theta \mid X)=\left(\prod_{m \in M} \prod_{t \in 2, \ldots, T} \operatorname{Pr}\left\{z_{t m}=1 \mid z_{t-1, m}^{o}\right\}^{z_{t m}^{o}}\left(1-\operatorname{Pr}\left\{z_{t m}=1 \mid z_{t-1, m}^{o}\right\}\right)^{\left(1-z_{t m}^{o}\right)}\right) \\
& \operatorname{Pr}\left\{z_{1 m}=1 \mid z_{0 m}^{o}=0\right\}^{z_{1 m}^{o}}\left(1-\operatorname{Pr}\left\{z_{1 m}=1 \mid z_{0 m}^{o}=0\right\}\right)^{\left(1-z_{1 m}^{o}\right)} . \\
& \left(\prod_{m \in M} \prod_{s \in S_{t m}} \prod_{t \in T}\left(L\left(e_{c h, t m}^{o} \mid z_{t m}^{o}=1\right) L\left(e_{t p s, t m}^{o} \mid z_{t m}^{o}=1\right)\right)^{z_{t m}^{o}}\right. \text {. } \\
& \left.L\left(e_{t p s, t m}^{o} \mid z_{t m}^{o}=0\right)^{1-z_{t m}^{o}}\right) .
\end{aligned}
$$

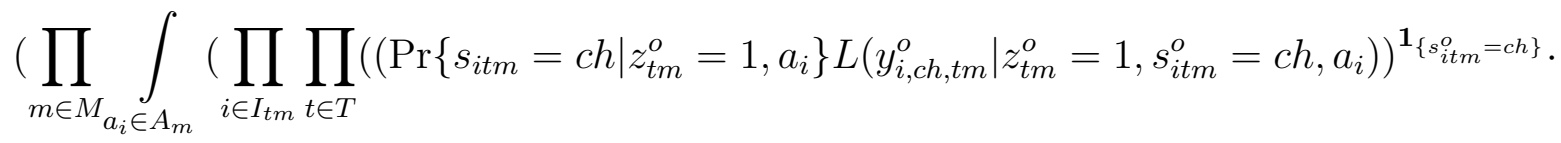

$$
\begin{aligned}
& \left.\left(\left(1-\operatorname{Pr}\left\{s_{i t m}=c h \mid z_{t m}^{o}=1, a_{i}\right\}\right) L\left(y_{i, t p s, t m}^{o} \mid z_{t m}^{o}=1, s_{i t m}^{o}=t p s, a_{i}\right)\right)^{\mathbf{1}_{\left\{s_{i t m}^{o}=t p s\right\}}}\right)^{z_{t m}^{o}} . \\
& \left.\left.L\left(y_{i, t p s, t m}^{o} \mid z_{t m}^{o}=0, s_{i t m}^{o}=t p s, a_{i}\right)^{1-z_{t m}^{o}}\right) d F_{m}\left(a_{i}\right)\right)
\end{aligned}
$$

I maximize the likelihood using APPSPACK (Gray and Kolda (2006)), which is a derivativefree optimization program that is designed for easy parallelization. I compute standard errors using the sum of the outer product of the observation-level scores. An observation is a market-level or household-level likelihood statement, where entry probabilities are included in the market-level statements.

\subsection{Identification}

\subsubsection{Market Ability Distributions}

The ability distribution for each market is assumed to be normally distributed. The market ability distribution is non-parametrically identified given the public school test score production function and test score productivity shock distribution (Refer to Appendix E for the proof). I assume market level ability is normally distributed to make some parts of the school objective much easier to solve. ${ }^{52}$ The market ability distribution enters both

\footnotetext{
${ }^{52}$ This can be seen when I derive the school objective in Section 2.4, where the measure of students attending a particular school from a certain distance bin can be written in terms of the normal distribution function. The average ability of students from each bin still requires integration over the ability distribution, which I do numerically when solving the model.
} 
the school problem through the charter school entry decision and subsequent school effort choices and student likelihood statements. In this section I show how I recover the mean and variance of each market's ability distribution. The recovered market ability distributions are functions of the public school test score production function parameters, so they must be recovered jointly with the estimation of the model. Market ability distributions are inherently unobservable; by recovering them I can treat them as being observed when I integrate over student ability in solving the school maximization problems and student likelihood statements.

I use the public school production function for 1997, the year before charter school authorization in North Carolina. Using the production function for public schools (1), the mean test score for market $m$ in $1997 \bar{y}_{t p s, 1997, m}$ is

$$
\begin{aligned}
\bar{y}_{t p s, 1997, m} & =\int_{a} \int_{\nu_{t p s}^{y}} y_{i, t p s, 1997, m} f_{\nu^{y}}\left(\nu_{t p s}^{y}\right) f_{m}(a) d \nu_{t p s}^{y} d a \\
& =\int_{a} a E y_{t p s}\left(e_{t p s, 1997, m}^{o}, 1, k_{t p s, 1997, m}\right) f_{m}(a) d a+\int_{\nu_{t p s}^{y}} f_{\nu^{y}}\left(\nu_{t p s}^{y}\right) d \nu_{t p s}^{y} \\
& =E y_{t p s}\left(e_{t p s, 1997, m}^{o}, 1, k_{t p s, 1997, m}\right) \int_{a} a f_{m}(a) d a+\underbrace{\mathrm{E}\left[\nu_{i, t p s, 1997, m}^{y}\right]}_{0} \\
& =\bar{a}_{m} E y_{t p s}\left(e_{t p s, 1997, m}^{o}, 1, k_{t p s, 1997, m}\right)
\end{aligned}
$$

where $f_{m}$, the ability distribution of market $m$, is assumed to be invariant over time in each market. The key here is that I can use the test score distribution before charter school entry to recover the parameters of the ability distribution because there was no choice of schools available in the year before entry, obviating controlling for selection on ability. Given data on the observed inputs in the market in 1997, $e_{t p s, 1997, m}^{o}$ and $k_{t p s, 1997, m}$, and the public school's test score production function parameters $\alpha_{t p s}, \beta_{t p s}$, and $\tau_{t p s}$, I can recover the mean ability for the market $\bar{a}_{m}$ jointly while estimating the rest of the model. Note here that the normalization of public school Hicks-neutral productivity parameter $\omega_{t p s}=1$ only affects the mean of recovered ability distributions, which means that the charter school's Hicks-neutral productivity parameter $\omega_{c h}$ can be thought of as productivity relative to that of a public school.

The variance of the test score $\sigma_{y, t p s, 1997}^{2}$ is a function of the variances of ability in market $m, \sigma_{a, m}^{2}$ and the test score productivity shock $\sigma_{\nu^{y}}^{2}$ and observed inputs

$$
\sigma_{y, t p s, 1997, m}^{2}=\sigma_{a, m}^{2}\left(E y_{t p s}\left(e_{t p s, 1997, m}^{o}, 1, k_{t p s, 1997, m}\right)\right)^{2}+\sigma_{\nu^{y}}^{2}
$$


If only data from 1997 are used for each market, the variance of the ability distribution cannot be separated from that of the test score productivity shock. I therefore fix $\sigma_{\nu^{y}}^{2}$ in the estimation. ${ }^{53,54}$ The chosen level of $\sigma_{\nu^{y}}^{2}$ affects the share of test score variance attributed to the ability distribution, which may affect outcomes for counterfactual scenarios by emphasizing its role relative to test score productivity shocks.

\subsubsection{School Effort}

I have data on effort, average weekly hours of homework done by students at each school, which means that it is trivially identified.

\subsubsection{Test Score Production Functions}

It is difficult to separate student ability from the productivity of school inputs in the presence of student sorting on ability, which the model predicts will typically occur. The productivity of inputs may be estimable due to restrictions imposed by functional form, but it is preferable to identify test score production function parameters using an exclusion restriction. I use data on the distance from a student to the public and charter schools in estimating the probability a student will attend the charter school. Changes in these distances, so long as they do not imply a change in the ability distribution, shift the probability a household would attend the charter school without changing the test score. This approach has been taken by others, such as Cullen et al. (2005), where the authors use distance from a school as an instrument for the probability of school attendance.

\subsection{Missing Data}

I assume data are missing randomly. There are some charter school observations where homework was not reported for any students, so those schools did not contribute to the effort likelihood. As I discussed in the sample restriction section, about $5 \%$ of observations in charter and public schools are missing test score data, so these students also do not contribute to the likelihood as they are excluded.

More importantly, about two-thirds of the students in charter schools are never observed attending public schools, which, when combined with the fact that charter schools tend not to report student locations, means that it is unlikely that I observe their addresses. ${ }^{55}$

\footnotetext{
${ }^{53}$ I fix $\sigma_{\nu^{y}}$ for both public and charter schools to be 0.40 .

${ }^{54}$ Although the variance of the test score productivity shock may be recovered using only the 1997 data, it is in theory possible to use more than one year of data to estimate it.

${ }^{55}$ The assumption that these addresses are missing at random may be justified by the fact that an indicator for whether the address is missing is not significantly associated with a student's test score when controlling
} 
I integrate the likelihood over market distance distributions for students missing location data.

\section{$5 \quad$ Estimation Results}

\subsection{Parameters}

Table 5 shows the estimated parameters for the model. The first seven rows are the test score production function parameters. Recall that all public schools share the same test score production technology and all charter schools share (a different) test score production technology. Both schools have effort shares in test score production that are higher than capital shares. Charter schools are closer to constant returns to scale than public schools $\left.\tau_{c h}=0.488>\tau_{t p s}=0.060\right)$. The elasticity of substitution between capital and effort is 0.54 for charter schools and 0.52 for public schools.

Household utility is denominated in test scores, so utility parameters are interpretable in terms of test scores, which have a standard deviation of 1 . The disutility of effort is negative $\left(c_{e}=-1.274\right)$, which means students prefer attending the school where they have to work harder, even after taking into account increased test scores. The per-kilometer distance cost is about one-fifth of a standard deviation $\left(c_{r}=0.219\right)$ of test scores. The disutility from attending a charter school is quite large $\left(c_{c h}=4.128\right)$, which is what allows the model to fit student school choice probabilities given the higher productivity of charter schools and the relatively small distance cost of commuting. ${ }^{56}$ This parameter may capture the fact that charter schools often have fewer extracurricular activities and capacity constraints on charter schools, which are not modeled. The disutility from attending a charter school increases with ability $\left(c_{c h, a}=0.247\right)$, which attenuates sorting on ability to charter schools.

In the school effort cost functions, charter schools have much larger diseconomies of scale from exerting effort than public schools $\left(\psi_{e, c h, 3}=3.192>\psi_{e, t p s, 3}=-0.041\right)$, although the parameter is imprecisely estimated for both school types. Both schools pay a cost of exerting effort that is mitigated by higher levels of capital $\left(\psi_{e, c h, 4}=-4.894, \psi_{e, t p s, 4}=-0.903\right) .{ }^{57}$ There may be an intuitive explanation for this: Higher per-pupil capital levels may make it easier for the school to create, assign, and grade homework because there are more computers per student or if there are smaller class sizes..$^{58}$

\footnotetext{
for student ethnicity.

${ }^{56}$ The distance cost is on average effectively larger for students to attend a charter school.

${ }^{57}$ This parameter is imprecisely estimated for both school types.

${ }^{58} \mathrm{In}$ addition to average test score $\bar{y}_{s}$, I also estimated a coefficient for total test score, $\mu_{s} \bar{y}_{s}$, at each school. These variables were noisily estimated and were not quantitatively important.
} 
Finally, to capture the persistence of charter school entry in the data, the mean of the entry cost shock distribution is much lower when there was a charter school in the market in the previous period $\left(\mu_{\underline{v} \text {,given entry }}=66<\mu_{\underline{v}}=179\right)$. Charter schools are also more likely to enter in markets the higher the share of the market is Black students $\left(\gamma_{f r \text {. Black }}=58\right)$, though this parameter is somewhat imprecisely estimated.

\section{$5.2 \quad$ Model Fit}

The model fits basic charter school entry, charter and public school effort, student choice, and student test score patterns for North Carolina. Table 6 shows the fraction of markets of certain characteristics with charter schools. The first row is the observed and predicted overall fraction of markets with charter schools over the estimation period 1998-2001. The model also captures the facts that charter schools are more likely to enter markets where they would receive higher per-pupil capital (rows 2 and 3) and that charter schools are more likely to open in larger markets (rows 4 and 5). ${ }^{59}$ Note that I am not explicitly targeting these moments in the data, but rather am trying to fit observed entry patterns for all markets using maximum likelihood.

Table 7 shows that the model is capable of reproducing patterns of the observed school effort levels in the data as measured by hours of homework: charter and public schools in markets in which charter schools operate exert higher levels of effort than monopolist public schools. This is because charter schools enter markets with both higher mean abilities and higher per-pupil capital levels, as well as the competitive effect of charter school entry. The table over-predicts effort levels of charter schools relative to their public school competitors, but captures the fact that both schools in markets with charters have higher effort levels than monopolist public schools. The table also shows that the model slightly over-predicts the standard deviation of chosen effort levels of charter schools (columns 3 and 4), though it captures the pattern that charter schools have more variation in chosen effort levels than public schools across markets. Table 8 shows that the model also captures the relationship between school capital and effort. Charter schools in markets where the charter schools have above median per-pupil capital exert more effort than they do in markets with below median per-pupil capital. The same is true for public schools both in markets with and without charter school entry. In general, schools exert higher effort in markets where they have higher per-pupil resources for two reasons: capital directly augments test score production and also makes effort exertion less costly for schools through the interaction between capital and effort in school effort cost functions. This latter effect is why public schools exert

\footnotetext{
${ }^{59}$ Recall that per-pupil capital at charter schools is based on a prediction, so it exists even in markets where the charter school has not entered.
} 
Table 5: Parameter Estimates

Parameter Estimate Standard error $\quad$ Description

\begin{tabular}{lcll}
\multicolumn{3}{l}{ Test score production functions } \\
\hline$\omega_{c h}$ & 1.612 & 0.064 & productivity of charter school relative to public \\
$\alpha_{c h}$ & 0.108 & 0.082 & effort share, charter school \\
$\beta_{c h}$ & -0.852 & 0.805 & substitution parameter, charter school \\
$\tau_{c h}$ & 0.488 & 0.038 & return to scale, charter school \\
$\alpha_{t p s}$ & 0.936 & 0.026 & effort share, public school \\
$\beta_{t p s}$ & -0.929 & 0.311 & substitution parameter, public school \\
$\tau_{t p s}$ & 0.060 & 0.005 & return to scale, public school \\
& & & \\
Student cost & & & \\
$c_{e}$ & -1.274 & 0.276 & student effort cost \\
$c_{r}$ & 0.219 & 0.051 & student distance cost \\
$c_{c h}$ & 4.128 & 0.904 & student charter school cost \\
$c_{c h, a}$ & 0.247 & 0.052 & student charter school cost interact ability
\end{tabular}

School preference shock

\begin{tabular}{llll}
\hline$\sigma_{\eta}$ & 2.499 & 0.559 & st. dev. student school preference shock
\end{tabular}

School valuation of test scores

\begin{tabular}{lccl}
\hline$\delta_{y, c h}$ & 29.788 & 12.965 & value of average test score, charter school \\
$\delta_{y, t p s}$ & 33.215 & 5.853 & value of average test score, public school
\end{tabular}

School effort cost functions

\begin{tabular}{lccl}
\hline$\psi_{e, c h, 1}$ & 0.996 & 1.563 & disutility of effort, charter school \\
$\psi_{e, t p s, 1}$ & 1.939 & 0.681 & disutility of effort, public school \\
$\psi_{e, c h, 2}$ & 1.212 & 0.352 & convex disutility of effort, charter school \\
$\psi_{e, t p s, 2}$ & 0.720 & 0.710 & convex disutility of effort, public school \\
$\psi_{e, c h, 3}$ & 3.192 & 2.162 & effort, school size interaction, charter school \\
$\psi_{e, t p s, 3}$ & -0.041 & 0.028 & effort, school size interaction, public school \\
$\psi_{e, c h, 4}$ & -4.894 & 3.189 & effort, capital interaction, charter school \\
$\psi_{e, t p s, 4}$ & -0.903 & 0.566 & effort, capital interaction, public school \\
Entry cost & & & \\
\hline$\mu_{\underline{v}}$ & 179.036 & 78.623 & mean entry cost distribution, no entry last period \\
$\sigma_{\underline{v}}$ & 35.831 & 21.179 & st. dev. entry cost distribution, no entry last period \\
$\mu_{\underline{v}, \text { given entry }}$ & 65.962 & 44.067 & mean entry cost distribution, entry last period \\
$\sigma_{\underline{v}, \text { given entry }}$ & 27.264 & 36.841 & st. dev. entry cost distribution, entry last period \\
$\psi_{f r . B l a c k}$ & 57.990 & 32.268 & weight for fraction of Black students in market \\
& & & \\
Effort productivity shocks & & \\
\hline$\sigma_{\nu_{c h}}$ & 0.427 & 0.025 & st. dev. effort productivity shock, charter school \\
$\sigma_{\nu_{e} p s}$ & 0.170 & 0.003 & st. dev. effort productivity shock, public school
\end{tabular}


Table 6: Fit: Charter School Entry Patterns by Market Characteristics

\begin{tabular}{lcc} 
& Observed & Predicted \\
\hline All markets & 0.056 & 0.061 \\
& & \\
Charter per-pupil capital & & \\
\hline above median $k_{c h}$ & 0.095 & 0.077 \\
below median $k_{c h}$ & 0.017 & 0.046 \\
& & \\
Market size & & \\
\hline above median $\mu$ & 0.067 & 0.067 \\
below median $\mu$ & 0.045 & 0.055
\end{tabular}

higher effort in markets where they have higher per-pupil capital in spite of the fact that the coefficient on per-pupil capital in the public school test score production function is small.

Table 7: Fit: Hours of Homework by School Type

\begin{tabular}{lcccc} 
& \multicolumn{2}{c}{ Mean } & \multicolumn{2}{c}{ Standard Deviation } \\
Entry Markets & Observed & Predicted & Observed & Predicted \\
\hline Charter Schools & 2.66 & 2.69 & 0.94 & 1.27 \\
Public Schools & 2.69 & 2.58 & 0.62 & 0.57 \\
& & & & \\
Monopoly Markets & & & & \\
\hline Public Schools & 2.43 & 2.43 & 0.47 & 0.49
\end{tabular}

Table 9 shows model fit for the fraction of students choosing charter schools. The model fits the pattern that charter schools are smaller than the public schools in markets they have entered. The first column, 0.0915, is the average for all markets with charter schools. The second column presents the total fraction of students choosing the charter school in markets with charters for the full simulation of the model - that is, first simulating charter school entry decisions and then school effort choices, and simulating student school choices based on predicted school effort choices. The last two columns are the observed and simulated total shares of students in charter schools. The model slightly over-predicts the overall share of charter schools in markets with entry and under-predicts the total number of students in charter schools. This under-shooting stems from simulated charter schools entering small markets more frequently than observed in the data (Table 6). This overall under-prediction attenuates the estimated impact of charter schools on the aggregate test score distribution, which is presented in the next section. 
Table 8: Fit: Mean Hours of Homework by School Type by Market Characteristics

\begin{tabular}{lcc}
$\begin{array}{l}\text { Entry Markets } \\
\text { Charter Schools }\end{array}$ & Observed & Predicted \\
\hline $\begin{array}{l}\text { above median } k_{c h} \\
\text { below median } k_{c h}\end{array}$ & 2.74 hours & 2.82 hours \\
& & \\
Public Schools & & 2.49 hours \\
\hline $\begin{array}{l}\text { above median } k_{t p s} \\
\text { below median } k_{t p s}\end{array}$ & 2.78 hours & 2.66 hours \\
& & \\
Monopoly Markets & & \\
Public Schools & & \\
\hline above median $k_{t p s}$ & 2.51 hours & 2.50 hours \\
below median $k_{t p s}$ & 2.35 hours & 2.37 hours
\end{tabular}

Table 9: Fit: Fraction of Students Choosing Charter Schools

\begin{tabular}{cc|cc}
\multicolumn{2}{c|}{$\begin{array}{c}\text { Entry Markets } \\
\text { Observed }\end{array}$} & \multicolumn{2}{c}{ Predicted Markets } \\
Observed & Predicted \\
\hline 0.0915 & 0.1156 & 0.0382 & 0.0109
\end{tabular}

Table 10 shows that the model captures the ranking average of test scores in the estimation sample: students at charter schools have the highest average test scores, followed by students attending public schools in markets charter schools have entered, followed by students in public schools in markets without charters. The fact that public schools are monolithic in test score production may explain the difference between predicted and simulated test scores: one test score production function must explain test scores in public schools with and without charter school entry. ${ }^{60}$

\footnotetext{
${ }^{60}$ Charter school test scores must be even higher to rationalize the school choice patterns in the data. Note that even though the model slightly over-predicts mean test scores for students attending charter schools, rankings of average test scores of charter schools, public schools in markets with charters, and monopolist public schools are recovered in the estimation. Nonetheless, this somewhat overstates the direct effect of charter school entry on test scores, which is presented in the next section.
} 
Table 10: Fit: Student Test Scores

\begin{tabular}{lcccc} 
& \multicolumn{2}{c}{ Mean } & \multicolumn{2}{c}{ Standard Deviation } \\
& Observed & Predicted & Observed & Predicted \\
\hline All Markets & 3.053 & 3.049 & 0.9509 & 0.9434 \\
& & & & \\
Entry Markets & & & & \\
\hline Charter Schools & 3.137 & 3.243 & 0.9381 & 1.049 \\
Public Schools & 3.075 & 3.074 & 0.9995 & 0.966 \\
& & & & \\
Monopoly Markets & & & & \\
\hline Public Schools & 3.028 & 3.045 & 0.9087 & 0.9396
\end{tabular}

\section{Counterfactual Simulations}

I use the developed model to simulate charter school entry decisions and school effort choices under entry and monopoly scenarios. I then simulate household school choices and test scores (i.e. potential outcomes) for each household in the market's charter school, traditional public school competitor, and monopolist public school. ${ }^{61} \mathrm{I}$ incorporate selection on student ability in two ways: I model charter school entry decisions as a function of market-level ability distributions, and within markets I model student sorting as a function of heterogeneous student ability and differential effective school inputs. ${ }^{62}$

The additional structure provided by the developed model allows me to make several contributions to the literature studying the effects of school choice. First, by providing a model for potential outcomes for each student, I can take into account the competitive effects of charter school entry on students in competing public schools. ${ }^{63}$

Second, I am not restricted to evaluating the effect of being in either charter or traditional public schools for students in their chosen school or in markets where charter schools have previously entered, but can estimate treatment effects for all students regardless of their observed school choice or charter school entry decisions. This ability to generalize treatment effects is useful for policymakers interested in expanding the scope of school choice programs such as charter schools.

\footnotetext{
${ }^{61}$ I simulate the full model 50 times.

${ }^{62}$ By "differential effective school inputs" I mean the difference in expected test scores under a treatment (attending a charter school or public school competing with a charter school) and under the monopoly scenario for a student with ability 1, e.g. $\overline{E y_{c h}\left(e_{c h, m}, 1, k_{c h, m}\right)-E y_{t p s}\left(e_{t p s, m}^{m o n o}, 1, k_{t p s, m}\right)}$ for the direct treatment and $\overline{E y_{t p s}\left(e_{t p s, m}, 1, k_{t p s, m}\right)-E y_{t p s}\left(e_{t p s, m}^{m o n o}, 1, k_{t p s, m}\right)}$ for the spillover.

${ }^{63}$ Rosenbaum and Rubin (1983) discuss potential outcomes in the context of matching estimators. Heckman et al. (1997) discuss potential outcomes in the context of heterogeneous treatment impacts.
} 
Third, in my framework all treatment effects are inherently heterogeneous both within markets, because students may differ by ability, and between markets, which may have different equilibrium charter school entry decisions, school inputs, and student characteristics.

Finally, I provide a framework that estimates both direct and spillover effects, in any environment, in the absence of lotteries or even panel data on students. This framework incorporates an administrative dataset of the kind increasingly being made available by states. $^{64}$

\subsection{Definitions}

There are two potential treatments: attending a charter school and attending a public school which is competing with a charter school. I define the effect of being in a charter school ("direct effect") for student $i$ who lives in market $m$ as the difference between the test score the student would have received at the charter school and that she would have received at a monopolist public school in that market: ${ }^{65}$

$$
\begin{aligned}
\Delta_{\text {im }}^{\text {direct }} & =y_{i, c h, m}-y_{i, t p s, m}^{\text {mono }} \\
& =E y_{c h}\left(e_{c h, m}, a_{i}, k_{c h, m}\right)+\nu_{i, c h}^{y}-E y_{t p s}\left(e_{t p s, m}^{\text {mono }}, a_{i}, k_{t p s, m}\right)-\nu_{i, t p s, m o n o}^{y}
\end{aligned}
$$

where $\nu_{i s}^{y}$ is the (additively separable) ex-post test score productivity shock for $i$ at school of type $s, e_{c h, m}$ is the equilibrium effort level chosen by the charter school in that market, and $e_{t p s, m}^{m o n o}$ is the effort level chosen by the monopoly public school in that market. ${ }^{66}$ The effect of attending a public school that is competing with a charter school ("spillover effect") for this student is

$$
\begin{aligned}
\Delta_{i m}^{s p i l l} & =y_{i, t p s, m}-y_{i, t p s, m}^{\text {mono }} \\
& =E y_{t p s}\left(e_{t p s, m}, a_{i}, k_{t p s, m}\right)+\nu_{i, t p s}^{y}-E y_{t p s}\left(e_{t p s, m}^{m o n o}, a_{i}, k_{t p s, m}\right)-\nu_{i, t p s, m o n o}^{y},
\end{aligned}
$$

where $e_{t p s, m}$ is the equilibrium effort level chosen by the traditional public school.

The model provides potential outcomes for all students, so the effects of either treatment (the direct effect of being in a charter school or the spillover effect from being in a public school competing with a charter school) can be calculated for any student regardless of

\footnotetext{
${ }^{64}$ Obama's Race to the Top initiative incentivizes states to build and make public statewide school system administrative datasets.

${ }^{65}$ In the model section there were no market or time subscripts because the analysis was done within one market and one time period. I drop the time subscript here to unclutter exposition, but add a market subscript to make clear comparisons across markets.

${ }^{66}$ In the model, chosen effort levels are then shocked with an effort productivity shock which I am abstracting from in the current exposition. All simulations reported here incorporate effort productivity shocks.
} 
choice. Researchers typically focus on mean treatment effects, which are expected values of $\Delta^{\text {direct }}$ and $\Delta^{\text {spill }}$ for different (and possibly choice-based) populations of students. Consider the treatment of attending a charter school. The mean direct effect of treatment on the treated (direct TOT) is the mean effect of attending a charter school among students who would choose it. ${ }^{67}$ In market $m$, the mean direct TOT is

$$
\begin{aligned}
\bar{\Delta}_{m}^{\text {direct }, \text { TOT }} & =\mathrm{E}\left[\Delta^{\text {direct }} \mid s_{i m}=c h\right] \\
& =\int \Delta_{i m}^{\text {direct }} f_{m}\left(a_{i m} \mid s_{i m}=c h\right) d a_{i m}
\end{aligned}
$$

where $f_{m}\left(a_{i m} \mid s_{i m}=c h\right)$ is the density of ability for students choosing the charter school in market $m$, which was derived in model equation (10). ${ }^{68,69}$ The mean direct effect of treatment on the untreated (TOU) in $m$ is the mean effect of attending a charter school among students who would choose the public school, i.e.

$$
\begin{aligned}
\bar{\Delta}_{m}^{\text {direct }, T O U} & =\mathrm{E}\left[\Delta^{\text {direct }} \mid s_{i m}=t p s\right] \\
& =\int \Delta_{i m}^{\text {direct }} f_{m}\left(a_{i m} \mid s_{i m}=t p s\right) d a_{i m}
\end{aligned}
$$

and the mean direct average treatment effect (ATE) in $m$ averages over all students in the market $\bar{\Delta}_{m}^{\text {direct, }, A T E}=\mathrm{E}\left[\Delta^{\text {direct }}\right]=\int \Delta_{\text {im }}^{\text {direct }} f_{m}\left(a_{i m}\right) d a_{i m}$, where $f_{m}$ is the density of ability in market $m$. Market mean spillover effects are calculated analogously, substituting $\Delta_{\text {im }}^{\text {spill }}$ for $\Delta_{i m}^{\text {direct }}$ and switching tps and $c h$ for student school choices.

To aggregate treatment effects across markets, I weigh market-level treatment effects by market size and entry status. For example, the mean direct TOT across all entry markets is

$$
\bar{\Delta}^{\text {direct,TOT,entry }}=\sum_{m} \mathbf{1}_{\left\{z_{m}=1\right\}} \mu_{c h, m} \bar{\Delta}_{m}^{\text {direct,TOT }} / \sum_{m} \mathbf{1}_{\left\{z_{m}=1\right\}} \mu_{c h, m},
$$

where $z_{m}=1$ indicates that the charter school has entered $m$ and $\mu_{c h, m}$ is the measure of students choosing the charter school in $m$. Other aggregated treatment effects are calculated analogously.

Researchers who exploit lotteries among applicants to an over-subscribed charter school compare test scores of students who applied to be in those charter schools and who were randomized into the charter school with those who were randomized out (therefore attend-

\footnotetext{
${ }^{67}$ I refer to the effect of choosing a treatment as treatment on the treated even in the case where a charter school has not entered (i.e. no students in that market have been treated).

${ }^{68}$ In the model, the derivation is presented by household distance from both schools, which I abstract from in the current exposition. All simulations use household distance from schools.

${ }^{69}$ Note that additive test score productivity shocks average out when computing all mean treatment effects.
} 
ing the traditional public school competitor). Denote the treatment effect estimated for household $i$ in such a study as $\check{\Delta}_{i m}^{\text {direct }}$, where

$$
\check{\Delta}_{\text {im }}^{\text {direct }}=y_{i, c h, m}-y_{i, t p s, m}=\Delta_{i m}^{\text {direct }}-\Delta_{i m}^{\text {spill }}
$$

i.e. $\check{\Delta}_{\text {im }}^{\text {direct }}$ is the difference between the direct and spillover effects of charter school entry for $i$. Intuitively, the more a public school changes in response to charter school entry, the more biased would be the lottery estimate of $i$ 's direct effect of charter school entry. Were a monopolist public school to drastically change its behavior due to charter school entry such that $\Delta_{\text {im }}^{\text {spill }}>\Delta_{\text {im }}^{\text {direct }}>0$, a researcher using a lottery design would surmise that the treatment effect of being in that market's charter school is negative for $i$, even though the direct effect is positive. Theory gives us no a priori sign on the spillover effect, which means even of sign this bias cannot be determined without further structure.

Even were there no spillover effect of charter school entry, researchers using lottery methods have noted that their estimates may not generalize to other existing charter schools or to charter schools that have not yet opened, if oversubscribed schools are different from those

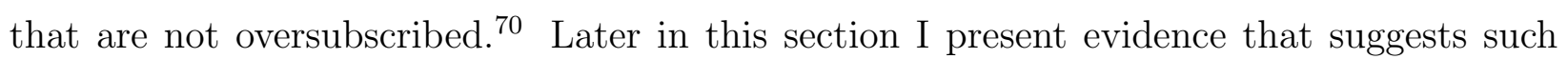
results may not generalize to charter schools in other markets.

\subsection{Effects of Charter Schools on the Distribution of Test Scores, 1998-2001}

Table 11 summarizes mean direct and spillover effects of charter schools on test scores for different populations of students for the estimation sample, which covers the period 19982001. It also reports the mean bias on the direct effect introduced by using an estimator that ignores the spillover effect of charter school entry (such as the lottery estimator). All results are reported in percentages of a standard deviation of the average of math and reading test scores. The top half of the table (Entry markets) reports results for markets in which charter schools are operating and the bottom half (Monopoly markets) report what results would be in those markets in which charter schools are not operating. ${ }^{71}$ The row within an entry status indicates which subset of households is being considered: all households in such markets (ATE), households who would choose charters, or households who would choose traditional public schools. For example, the number associated with the first column $\left(\bar{\Delta}^{\text {direct }}\right)$ and the row "Attend public" in the top half of the table is the the mean direct effect

\footnotetext{
${ }^{70}$ Angrist et al. (2010) note this in their paper on a Massachusetts charter school.

${ }^{71}$ Although there are no charter schools operating in monopoly markets, the treatment effects are computed in the event a charter school were to enter and compete with the traditional public school.
} 
of treatment on the untreated in entry markets, $\bar{\Delta}^{\text {direct,TOU,entry }}$, i.e. the mean direct effect for students who did not choose the charter school, but instead chose the public school, in markets where charter schools are present.

Table 11: Mean Direct and Spillover Treatment Effects by School Choice in Entry and Monopoly Markets

\begin{tabular}{|c|c|c|c|c|}
\hline Entry markets & $\bar{\Delta}^{\text {direct }}$ & $\check{\check{\Delta}}^{\text {direct }}$ & $\overline{\left(\Delta^{\text {direct }}-\check{\Delta}^{\text {direct }}\right)}$ & $\bar{\Delta}^{\text {spill }}$ \\
\hline ATE & 0.225 & 0.212 & 0.013 & 0.013 \\
\hline Attend charter & 0.246 & 0.240 & 0.006 & 0.006 \\
\hline Attend public & 0.222 & 0.208 & 0.014 & 0.014 \\
\hline \multicolumn{5}{|c|}{ Monopoly markets } \\
\hline ATE & 0.192 & 0.185 & 0.007 & 0.007 \\
\hline Attend charter & 0.208 & 0.208 & 0.000 & 0.000 \\
\hline Attend public & 0.190 & 0.182 & 0.008 & 0.008 \\
\hline
\end{tabular}

The first column shows the mean direct effect of charter school entry is highest for students who choose to attend charter schools in markets in which charter schools are operating, about $25 \%$ of a standard deviation in test scores. The third and fourth columns show the mean bias induced in the estimation of direct effects by ignoring spillover effects (column 2) and spillover effects of charter school entry, and are therefore equal. The overall amount of bias introduced by ignoring spillover effects is very small, on the order of (or even less than) $1 \%$ of a standard deviation in test scores. Average treatment effects are much closer to the estimated effects for students attending public schools because the share of students attending charter schools is small (about $11 \%$ of entry markets). The ATE direct is almost $23 \%$ of a standard deviation. This table also shows that there is little evidence of sorting on ability between charter and public schools in entry markets.

Most of the direct effect comes from charter school technology. The mean test score for students in entry markets who attend charters is 3.243. If instead I simulate test scores for the same group of students using charter school inputs and public school technology the test score is reduced to 3.05. The mean test score is reduced by a much smaller amount if I also use monopoly public school inputs, to 3.0 .

Mean treatment effects are smaller in monopoly markets. The mean direct TOT of charter schools would be about $4 \%$ of a standard deviation lower in monopoly markets than they were in entry markets. Mean spillover effects are slightly smaller than they would have been in entry markets. These differences are again driven mostly due to lower levels of public and charter school inputs chosen in those markets. The average difference in effective inputs, 
$\overline{E y_{c h}\left(e_{c h}, 1, k_{c h}\right)-E y_{t p s}\left(e_{t p s}^{\text {mono }}, 1, k_{t p s}\right)}$, between charter schools and monopolist public school in entry markets is 0.0886 , while the same difference in monopoly markets is 0.072 , an $18 \%$ difference.

Although estimated treatment effects are a combination of state-level charter school authorization laws and other institutional characteristics, market- and school-level characteristics, student characteristics, and identification strategy, one may want to compare the results presented here with those in lottery studies. ${ }^{72}$ Angrist et al. (2010) find using a lottery on an oversubscribed Massachusetts KIPP school that students randomized into charters have 0.36 standard deviations higher math test scores and 0.12 standard deviations higher reading test scores than applicants randomized into competing traditional public schools. The outcome in this paper is the average of reading and math test score, so their finding of a $24 \%$ of a standard deviation increase in test scores for $\check{\Delta}^{\text {direct }}$ is similar to my finding of $25 \%$. Again, they estimate the direct effect of TOT on a selected set of charter school students in one oversubscribed charter school, which they acknowledge may not generalize to other students and charter schools in Massachusetts.

\subsubsection{Heterogeneity of Treatment Effects by Market}

Figure 2 plots mean market-level direct and spillover TOT for all markets, including those where charter schools are not present. There is substantial variation in mean market-level direct effects of TOT, although it is simulated to be negative in only a few markets. The 75 th percentile mean market-level direct TOT is 0.22 , double the 25 th percentile value of 0.11. There is relatively much less variation in mean spillover TOT, which is due to the relative ineffectiveness of public school inputs. Figure 3 is a histogram of mean market-level direct TOTs. The distribution is quite heterogeneous.

One might expect those charter schools that would benefit students the most would be in highest demand. Lottery studies basing direct TOT estimates on such charter schools may therefore by design be considering only certain part of the distribution of charter school treatment effects. Figure 4 plots mean direct TOT effects for each market as a function of the measure of students within that market who would choose to attend the charter school if available. In markets with below-median demand for charter schools (i.e. those with a below-median measure of students who would choose the charter school, were it to enter), the mean direct TOT is $16.7 \%$ of a standard deviation in test scores, compared with $18.1 \%$ for markets with above-median demand - an $8 \%$ difference. This figure shows the difficulty

\footnotetext{
${ }^{72}$ Panel data studies such as Hanushek et al. (2007), Sass (2006), and Bifulco and Ladd (2006) effectively compare differences in growth rates in test scores of students attending and not attending charter schools and are difficult to interpret in my framework.
} 
Figure 2: Market-Level Mean TOT Direct vs TOT Spillover

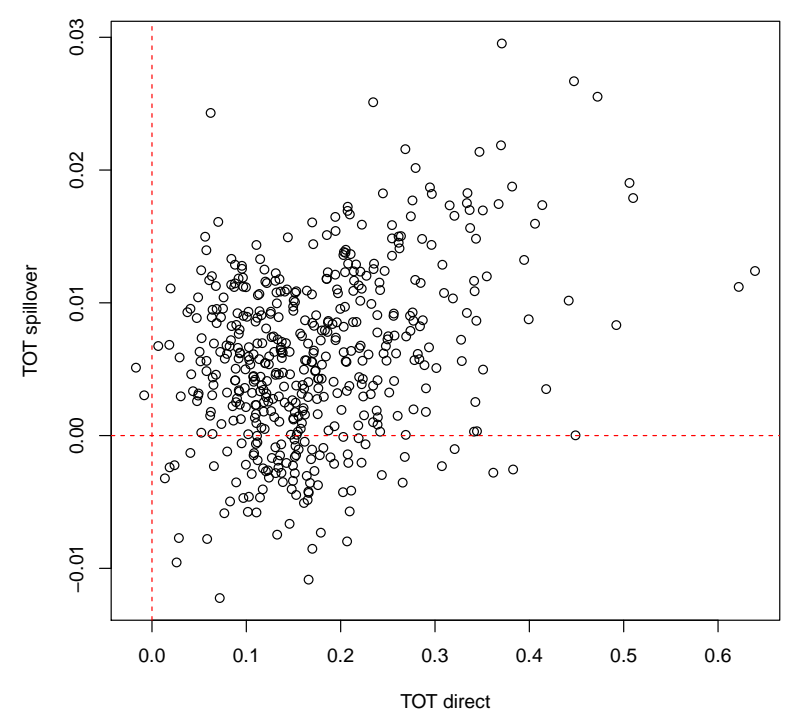

Figure 3: Distribution of Market-Level Mean Direct TOT

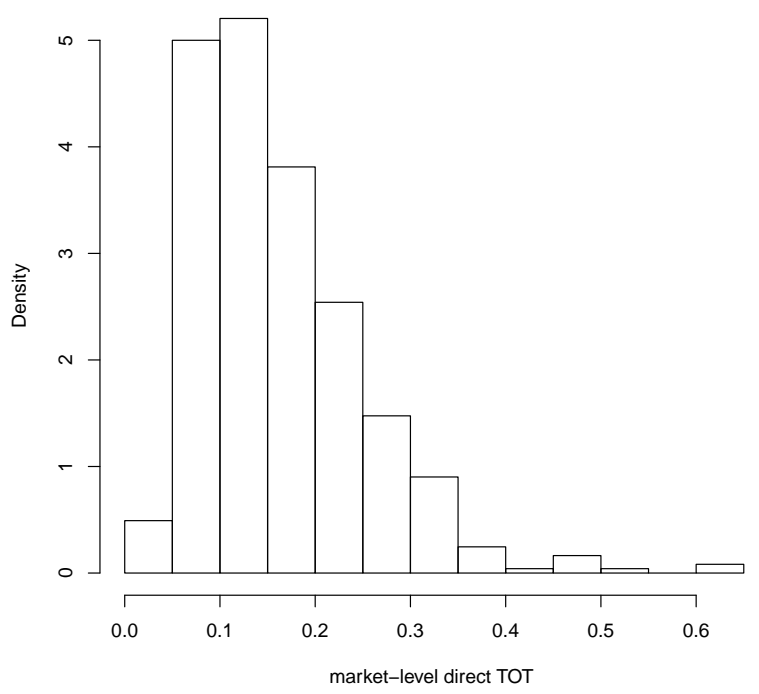

in generalizing findings from studies of only very popular (and therefore highly demanded) charter schools. ${ }^{73}$

\subsubsection{Interpreting the Direct ATE}

Upon seeing that the direct ATE is positive on average across markets both with and without charter schools, and that very few charter schools have negative direct effects on attendant students, one might be tempted to increase the market share of charter schools. However, the results from Table 11 are all partial equilibrium in the sense that, even though they take into account the equilibrium interactions of charter and public schools, both of which are also taking into account household sorting on ability, the interpretation of the treatment effects is only valid for an infinitesimal household switching from a treatment school to the monopolist public school. ${ }^{74}$ In response to a policy intervention that ignores the general equilibrium effects of increasing the share of students served by charter schools, I explore here how making charter schools monopolists, by assigning all students in a market to them after they have entered, would affect the distribution of student test scores. ${ }^{75}$ I allow charter

\footnotetext{
${ }^{73}$ The finding is qualitatively similar if I plot the market-level direct TOT by the fraction of students within a market who would attend a charter school.

${ }^{74}$ Heckman et al. (1998) investigate general equilibrium effects of tuition subsidies, and find that equilibrium effects on prices drastically alter their results.

${ }^{75}$ Taber (2001) considers a similarly extreme counterfactual policy in his study of the rising college wage premium.
} 
Figure 4: Mean TOT Direct by Demand for Charter School

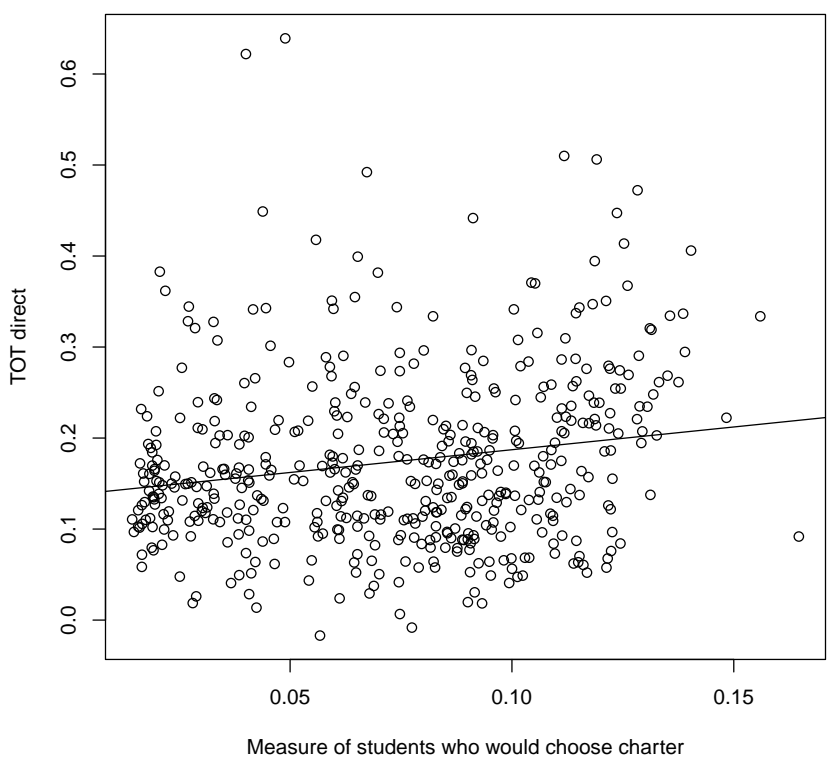

schools to re-optimize both entry and effort decisions knowing that they will serve all students in those markets they enter. In this scenario the direct effect of attending a charter school for student $i$ is defined as $\Delta_{i m}^{\text {direct }}=y_{i, c h, m}^{\text {mono }}-y_{i, t p s, m}^{\text {mono }}$, where $y_{i, c h, m}^{\text {mono }}$ is the test score for $i$ at a monopolist charter school exerting effort $e_{c h, m}^{\text {mono }}$.

Table 12 compares entry patterns for charter schools under the duopoly scenario and under the extreme case where they have been forced to serve all students in any markets they enter. Charter schools enter far fewer markets and are much more likely to enter markets with higher average test scores in 1997 (which are used to recover market ability distributions).

Table 12: Fraction of Markets with Entry by 1997 Average Test Score, Partial vs General Equilibrium

\begin{tabular}{ccc} 
& Partial Equilibrium & General Equilibrium \\
\hline Above median $\bar{y}_{1997}$ & 0.059 & 0.029 \\
Below median $\bar{y}_{1997}$ & 0.063 & 0.007
\end{tabular}

Table 13 is a population-weighted presentation of the TOT results from Table 11 for markets where charter schools are operating. ${ }^{76}$ The rows indicate the relevant set of students

\footnotetext{
${ }^{76} \mathrm{I}$ use $\mu_{m}$, the measure of students in that market, as weights. The estimation sample used a random
} 
(those in entry markets, in charter schools or public schools in entry markets, and all students). The first two columns are population weighted results from Table 11, with "partial equilibrium" charter school entry patterns provided by the model as estimated under the status quo. Within each pair of columns is first a column showing the share of all students (statewide) in the relevant group and then a column indicating the average increase in test score resulting from charter school entry for that group. The middle two columns assume charter schools are now monopolists, but using entry simulated under the duopoly scenario. The last two columns report results for the model solved when charter schools are both forced to be monopolists where they enter, and entry patterns are subsequently affected.

Weighing the results of Table 11 by population does not significantly alter the results (column 1), but due to the very small share of students statewide in charter schools (1.1\%), and fairly small spillover TOT, their overall effect on the test score distribution is negligible. When charter schools are forced to enter where they would have in the duopoly scenario (columns 3 and 4), they reduce effort inputs due to large diseconomies of scale in the charter school effort cost function. This results in average test scores gains of $15 \%$ of a standard deviation, which is lower than the direct ATE in entry markets from Table 11. In the last two columns, charter schools enter far fewer markets and affect only $2.0 \%$ of students, yet those markets that they do enter have higher mean abilities. This accounts for higher direct TOT, even though charter school effort drops drastically (from 2.69 to 1.46 hours per week).

Table 13: Population Weighted TOT Effects, Partial vs General Equilibrium

\begin{tabular}{l|cc|cc|cc} 
& $\begin{array}{c}\text { Partial Equil. Entry, } \\
\text { Partial Equil. Effort }\end{array}$ & $\begin{array}{c}\text { Partial Equil. Entry, } \\
\text { General Equil. Effort }\end{array}$ & $\begin{array}{c}\text { General Equil. Entry, } \\
\text { General Equil. Effort }\end{array}$ \\
Group & Share in Group & TOT & Share in Group & TOT & Share in Group & TOT \\
\hline Entry markets & 0.105 & 0.042 & 0.105 & 0.146 & 0.027 & 0.190 \\
Attend charter & 0.011 & 0.254 & 0.105 & 0.146 & 0.027 & 0.190 \\
Attend public & 0.094 & 0.017 & 0.000 & 0.000 & 0.000 & 0.000 \\
\hline All markets & 1.000 & 0.004 & 1.000 & 0.015 & 1.000 & 0.004
\end{tabular}

sample of students from monopoly markets and therefore needs to be re-weighted appropriately to incorporate market size heterogeneity. 


\subsection{The Effect of Allowing Unlimited Charter School Entry on Test Scores}

I now examine how lifting the cap on the total number of charter schools in North Carolina would affect the fraction of markets with charter schools and distribution of test scores in those markets and statewide. Recall from Section 3.2 that I avoid explicitly modeling the cap on charter schools by estimating the model using data from years well before the statewide cap in North Carolina started binding. Therefore, I can use the model as it was estimated and solve it for the years 2002-2005-when the cap was binding in North Carolina-to quantify the effect of allowing unrestricted charter school entry on the distribution of test scores.

The results suggest the cap on the total number of charter schools in North Carolina was binding. On average, during 2002-2005 charter schools operate in 15\% of markets, up from $6 \%$ for the period 1998-2001. Table 14 shows that the mean direct and spillover TOT impacts of charter schools in new entry markets are similar to those estimated for the first four years of charter school authorization. A much larger share of students are now in markets where charter schools operate (21\% up from 11\%) and that both TOT are slightly lower on average than they were for the previous period. The statewide increase in mean test scores is higher $(0.6 \%$ of a standard deviation) due to the larger share of students affected by either treatment.

Table 14: Population Weighted TOT Effects, 2002-2005

\begin{tabular}{lcc} 
Group & Share in Group & TOT \\
\hline Entry markets (avg. of direct and spillover TOT) & 0.207 & 0.031 \\
Attend charter (direct TOT) & 0.019 & 0.211 \\
Attend public (spillover TOT) & 0.188 & 0.013 \\
\hline All markets & 1.000 & 0.006 \\
\hline
\end{tabular}

\section{Conclusion}

I developed and estimated a structural model of charter school entry, student school choices, and endogenous school inputs. The model fits key patterns in the data. I demonstrate that both the direct effect and spillover effects of charter school entry are positive, although the direct effect is much larger than the spillover effect of charter schools on public school students. The direct effect of charter school entry is quite heterogeneous across markets. I also estimate that caps on the total number of charter schools were indeed binding, and that 
the test score distribution in new entry markets would be affected in a manner similar to those entered before caps started to bind.

\section{References}

Angrist, J., S. Dynarski, T. Kane, P. Pathak, and C. Walters (2010): "Who Benefits From KIPP?" NBER Working Paper.

Bettinger, E. (2005): "The Effect of Charter Schools On Charter Students and Public Schools," Economics of Education Review, 24, 133-147.

Bifulco, R. And H. LAdD (2006): "The Impacts of Charter Schools On Student Achievement: Evidence From North Carolina," Education Finance and Policy, 1, 50-90.

- (2007): "School Choice, Racial Segregation, and Test-Score Gaps: Evidence From North Carolina's Charter School Program," Journal of Policy Analysis and Management, 26,31 .

Bulow, J., J. Geanakoplos, and P. Klemperer (1985): "Multimarket Oligopoly: Strategic Substitutes and Complements," The Journal of Political Economy, 93, 488-511.

Chakrabarti, R. (2008): "Can Increasing Private School Participation and Monetary Loss in a Voucher Program Affect Public School Performance? Evidence From Milwaukee," Journal of Public Economics, 92, 1371-1393.

Cullen, J., B. Jacob, And S. LevitT (2005): "The Impact of School Choice On Student Outcomes: An Analysis of the Chicago Public Schools," Journal of Public Economics, 89, 729-760.

(2006): "The Effect of School Choice On Participants: Evidence From Randomized Lotteries," Econometrica, 74, 1191-1230.

Epple, D., M. Ferreyra, And B. Gordon (2011): "Charter School Entry in Market Equilibrium," working paper.

Epple, D. And R. Romano (1998): "Competition Between Private and Public Schools, Vouchers, and Peer-Group Effects," American Economic Review, 88, 33-62.

Ferreyra, M. (2007): "Estimating the Effects of Private School Vouchers in Multidistrict Economies," The American Economic Review, 789-817. 
Gleason, P., M. Clark, C. Tuttle, and E. Dwoyer (2010): "The Evaluation of Charter School Impacts: Final Report. NCEE 2010-4029." National Center for Education Evaluation and Regional Assistance, 259.

Google (2010): "Google Earth (Version 5.1.3535.3218)," .

Gray, G. and T. Kolda (2006): "Algorithm 856: APPSPACK 4.0: Asynchronous Parallel Pattern Search for Derivative-Free Optimization," ACM Transactions on Mathematical Software (TOMS), 32, 485-507.

Hanushek, E., J. Kain, S. Rivkin, and G. Branch (2007): "Charter School Quality and Parental Decision Making with School Choice," Journal of Public Economics, 91, 823 -848 .

Heckman, J., L. Lochner, and C. Taber (1998): "General-Equilibrium Treatment Effects: A Study of Tuition Policy," The American Economic Review, 88, 381-386.

Heckman, J., J. Smith, and N. Clements (1997): "Making the Most Out of Programme Evaluations and Social Experiments: Accounting for Heterogeneity in Programme Impacts," The Review of Economic Studies, 64, 487-535.

Hoxby, C. And J. Rockoff (2004): "The Impact of Charter Schools On Student Achievement," Harvard University, November.

Imberman, S. (2011): "The Effect of Charter Schools On Achievement and Behavior of Public School Students," Journal of Public Economics.

KIPP (2010): "KIPP: Knowledge Is Power Program," .

NCES (1998): "Universe of Public Elementary and Secondary Education Agencies - Fall 1997," .

Nechyba, T. (2000): "Mobility, Targeting, and Private-School Vouchers," American Economic Review, 90, 130-146.

Nichols, A. (2003): "VINCENTY: Stata Module to Calculate Distances On the Earth's Surface," Statistical Software Components, Boston College Department of Economics.

PicARD, R. (2010): "GEONEAR: Stata Module to Find Nearest Neighbors Using Geodetic Distances," Statistical Software Components, Boston College Department of Economics.

Rivkin, S., E. Hanushek, And J. Kain (2005): "Teachers, Schools, and Academic Achievement," Econometrica, 73, 417-458. 
Robertson, G. D. (2011): "Senate OKs Bill to Lift Charter School Cap," News Observer.

Rosenbaum, P. And D. Rubin (1983): "The Central Role of the Propensity Score in Observational Studies for Causal Effects," Biometrika, 70, 41-55.

SAss, T. (2006): "Charter Schools and Student Achievement in Florida," Education Finance and Policy, 1, 91-122.

Sundaram, R. (1996): A First Course in Optimization Theory, Cambridge University Press.

Taber, C. (2001): "The Rising College Premium in the Eighties: Return to College or Return to Unobserved Ability?" Review of Economic Studies, 68, 665-691.

White, J. (2009): "States Open to Charters Start Fast in 'Race to Top'," Press Release, US Department of Education, http://www2.ed.gov/news/pressreleases/2009/ 06/06082009a.html.

Wilder, M. (2010): "Candidates for Legislature, School Board Talk Education," The Times News.

Wiswall, M. (2011): "The Dynamics of Teacher Quality," . 


\section{A Existence of Equilibrium}

The proofs are for the case where there are no productivity shocks to the school's chosen effort level. The results go through in the case where there are shocks.

In order to use Brouwer's Fixed Point Theorem, the pair of best-response functions must be continuous self-map on a compact and convex set. First, I prove there is a unique best response of one school to another, then that this best response function is continuous, and finally apply Brouwer's Fixed Point Theorem. Note that for this I assume certain restrictions on the parameter space: a production function with Inada conditions and a convex effort cost.

Lemma 1. $e_{c h}^{*}=\arg \max _{e \in E} v_{c h}\left(e \mid e_{t p s}, x, \theta\right)$ is strictly positive.

Proof. First, note that $v_{c h}\left(0 \mid e_{t p s}, x, \theta\right)=\delta_{\mu, c h} \mu_{c h}\left(0, e_{t p s} \mid x, \theta\right)$, where $\mu_{c h}(\cdot) \geq 0$. Second, $\lim _{e_{c h} \rightarrow 0} \frac{\partial v_{c h}\left(0 \mid e_{t p s}, x, \theta\right)}{\partial e_{c h}}=\infty$ due to the Inada conditions on the test score production function, because there will always be some measure of students attending the charter school due to the preference shocks.

Call $v_{c h}^{+}=\max \left\{v_{c h}, 0\right\}$. Note that $v_{c}^{+}$is strictly quasi-concave, due to the strict concavity of $v_{c h}$ when it is above 0 .

Lemma 2. The effort set $E=[\underline{e}, \bar{e}]$ is compact.

Proof. Let $\underline{e}=0$. Given any allowable vector of parameters $\theta$ there exists $\bar{e}_{\theta}$ such that $v_{c h}(\hat{e})<0$, all $\hat{e}>\bar{e}_{\theta}$. Let $\bar{e}=\max _{\theta} \bar{e}_{\theta}$. It exists, so the set is not empty.

Lemma 3. $\gamma_{c h}$ is continuous

Proof. Berge's Maximum Theorem (Sundaram (1996)) requires a continuous objective $v_{c h}^{+}$, and compact and upper-hemicontinuous constraint set. Note first that the constraint set, $E$, is a fixed connected interval, so it is trivially UHC. $v_{c h}^{+}$is continuous, so the Maximum Theorem says the resulting correspondence which is the $\operatorname{argmax}$ of $v_{c h}^{+}$is UHC. Because $v_{c h}^{+}$is strictly quasi-concave, there is a unique argmax to $v_{c h}^{+}$, which means that $\gamma_{c h}$ is a continuous function.

Lemma 4. There exists an equilibrium to the entry subgame.

Proof. Since $\Gamma\left(e_{c h}, e_{t p s} \mid x, \theta\right)=\left(\gamma_{c h}\left(e_{t p s} \mid x, \theta\right), \gamma_{t p s}\left(e_{c h} \mid x, \theta\right)\right)$ is a continuous self map on the compact and convex domain $E^{2}$, there exists an equilibrium by Brouwer's Fixed Point Theorem. 


\section{B Uniqueness of Equilibrium}

I cannot prove uniqueness equilibrium in the entry subgame but can rule out multiplicity of the charter school entry decision, given a unique equilibrium in the ensuing entry subgame.

Lemma 5. There is no multiplicity in the charter school entry decision given uniqueness of equilibrium in the entry subgame.

Proof. The charter school only receives one shock $\underline{v}_{t m}$, which it knows. It enters if and only if

$$
\mathrm{E}_{\nu^{e}}\left[v_{c h, t m}^{*} \mid \nu^{\mathbf{e}}\right] \geq \underline{v}_{t m}
$$

where $\mathrm{E}_{\nu^{e}}\left[v_{c h, t m}^{*} \mid \nu^{\mathbf{e}}\right]$ is known since under the assumption of the lemma there is a unique equilibrium in chosen effort levels of the entry subgame.

Although I do not have a proof that the entry subgame has a unique equilibrium, I have searched for more than one equilibrium for a wide range of parameter values and have never found more than one equilibrium in a market. Intuitively, there will not be multiple equilibria in the entry subgame so long as schools are not too responsive to each other, which may be satisfied if the effort cost is sufficiently convex. I assume for the sake of estimation that even if there are multiple equilibria for the entry subgame both schools know which equilibrium they are in, and that they always play the same equilibrium.

\section{Construction of Capital Variable}

There are several measures of school resources for charter and public schools in the NCERDC data, but many are missing for many schools - especially charters. Moreover, I do not observe any school-specific resources for charter schools in markets where there was no charter school entry, which are an input into the test score production function and are therefore necessary for calculating the probability of charter school entry in a particular market. Finally, it is not obvious how the different measures of school resources should enter into the test score production function. What I need is a way to compute the subjunctive level of capital for both charter and public schools given information that is always observable for the a market. Here is how capital is constructed:

1. Convert measures (computers/pupil, teachers/pupil, experienced teachers/pupil) to percentiles.

2. Average (unweighted) these percentiles into one index for each school. 
3. Regress this index on inflation-adjusted per-pupil expenditures for the public school in each market, using separate regressions for charter and public schools.

4. Use the predicted value from the above regression as the capital measure for that school type in that market.

This measure always exists, so long as I have data on the per-pupil expenditures for the public school in that market. ${ }^{77}$ The last step obviates my having to integrate over the errors in the cost functions when solving the charter school's entry problem. Also, it precludes a role for charter schools making entry decisions based on unobservable information - that is, the predicted per-pupil capital levels are no different in expectation in entry and non-entry markets with the same level of per-pupil expenditures. Although such variation may play a role in charter school entry, I believe it is second order in understanding charter school entry patterns. Finally, note that since capital is percentile-based, the model would predict that rank-preserving changes in the capital distribution would have no effect in the economy.

\section{Construction of Distance Distribution}

I need a distribution of distances for each market in order to solve for the equilibrium of the entry subgame. There are two steps involved: 1) I discretize the distance distribution and 2) I model what the distance distribution would be in a market where I do not observe charter school entry, which is key for evaluating the probability that a charter school will enter a market.

\section{D.1 Discretization of Distance Distribution}

The data provide me with a continuous distribution of student distances, but I discretize this distribution to avoid making an expensive two-dimensional integration over both ability and distance for students when computing the value of the school objective functions when solving for entry subgame equilibria. I allocate each student in every market-time unit to one of four bins, where each bin represents a different set of distances to charter and public schools. A student is allocated to a bin if its distance to each school falls within the distance cut-offs for that particular bin. For example, take a market with 3 students, $j, k$, and $l$,

\footnotetext{
${ }^{77}$ Details available upon request.
} 
where the distances $r_{i s}$ are

\begin{tabular}{ccc} 
Student & $r_{i, c h}$ & $r_{i, t p s}$ \\
\hline$j$ & 0.5 & 1.1 \\
$k$ & 2 & 0.75 \\
$l$ & 2.5 & 0.25
\end{tabular}

I use the the median distance to the public school, 0.75, as the cut-off, so the criteria for the four bins are

$$
\begin{array}{lll}
\text { Bin } & & \\
\hline 1 & \{i: & \left.r_{i, c h} \leq 0.75, r_{i, t p s} \leq 0.75\right\} \\
2 & \{i: & \left.r_{i, c h}>0.75, r_{i, t p s} \leq 0.75\right\} \\
3 & \{i: & \left.r_{i, c h} \leq 0.75, r_{i, t p s}>0.75\right\} \\
4 & \{i: & \left.r_{i, c h}>0.75, r_{i, t p s}>0.75\right\}
\end{array}
$$

The distance vectors and measure of the population in each bin are

$$
\begin{aligned}
\vec{r}_{c h} & =\left[\begin{array}{llll}
-, & 2.25, & 0.5, & -
\end{array}\right] \\
\vec{r}_{t p s} & =\left[\begin{array}{llll}
-, & 0.50, & 1.1, & -
\end{array}\right] \\
\vec{\mu} & =\left[\begin{array}{cccc}
0, & \frac{2}{3}, & \frac{1}{3}, & 0
\end{array}\right]
\end{aligned}
$$

where I average over all the students in a bin to obtain the distance vector for that bin. For example, there are no students within $0.75 \mathrm{~km}$ from both the charter and public school, so the first entry in $\vec{\mu}$ is 0 , and the first entries of $\vec{r}_{c h}$ and $\vec{r}_{t p s}$ are undefined. There are two students $(k$ and $l$ ) more than $0.75 \mathrm{~km}$ from the charter school and within 0.75 of the public school, so the second element of $\vec{\mu}$ is $2 / 3$, and the average distance of students in the second bin from the charter school is 2.25 , while the average distance for students in the second bin from the public school is $0.5 \mathrm{~km}$.

\section{D.2 Model for Distance Distribution}

As with capital, I need to know what the distance distribution would be for all markets in order to calculate the value the charter school would expect to obtain upon entry, which then enters the expression for probability of entry. I first regress elements of $\vec{r}_{c h}$ and $\vec{r}_{t p s}$ and $\vec{\mu}$ on a 2-bin distribution (fraction of students within median distance to the public school and further than median distance to the public school, and average the distance for within-median and beyond-median students) for public schools in markets where I observe charter school entry. I then normalize the elements of the predicted fraction of students in each bin to sum to 1 for each market. I use the relationship as the distance distribution for all markets because the 2-bin distribution for distance to the public school is available in all 
markets.

\section{D.3 Discussion of My Assumptions about Distance}

First, this in no way helps explain why charter schools locate where they do within a district. In the data, they are, on average, however, further than public schools for most students within a district. This may be so because districts are designed around public schools, meaning charters may be relegated to locations not at the center of population mass.

Second, I could have had the schools integrate over the pair of continuous distance distributions when solving their problems, but I discretize it when solving their problems because I have to solve for the ability distribution for every point in the distance distribution.

Third, note that I assign all students in markets where charters do no enter the same distance to the charter school, because otherwise this argument is missing. This simplification does not effect the estimation, since within those districts, I do not observe students attending charters (since there are no charters). What matters in such districts is the probability of charter school entry, which is a function of the distribution of student distances for public schools and charters. I could alternatively have given the charter schools the same distance distribution as public schools when I do not observe charter school entry. Although simpler, this may introduce a bias in the estimation of the charter school operating cost distribution, because in the data charters are on average further from students than public schools.

Finally, note that, similar to my treatment of capital, these assumptions do not allow schools to select districts based on unobservable information about distance. This may be interesting, but it is not a first-order consideration because I am using distance as a demand shifter for student school choice, and my model picks up many other determinants of charter school entry.

\section{E Nonparametric Identification of Market Ability Dis- tributions}

I now prove that the unobservable market-level ability distributions are non-parametrically identified, given the public school's test score production function. Recall that no charter schools were open in 1997, so all students in all markets attended monopolist public schools in that year. The test score production function for public schools in market $m$ in 1997 is

$$
y_{i, t p s, 1997, m}=a_{i} \underbrace{\left(\alpha_{t p s}\left(e_{t p s, 1997, m}^{o}\right)^{\beta_{t p s}}+\left(1-\alpha_{t p s}\right) k_{t p s, 1997, m}^{\beta_{t p s}}\right)^{\tau_{t p s} / \beta_{t p s}}}_{x_{1997, m}}+\nu_{i, t p s, 1997, m}^{y}
$$


where $x_{1997, m}>0$ is a known constant given production function parameters and inputs $e_{t p s, t, m}^{o}$ and $k_{t p s, t, m}$. The ex-post productivity shock $\nu_{i, t p s, t, m}^{y}$ is assumed to be distributed independently from student ability and school inputs. This latter assumption is innocuous: even were households of different ability levels to differentially sort on test score shocks when charter schools were present there was no school choice in 1997 . Let $f_{1997, m}^{y}$ denote the observed distribution of $y_{i, t p s, 1997, m}$ and $f_{\nu^{y}}$ denote the distribution of $\nu^{y}$.

The problem is that ability is unobserved and each market's distribution of ability is a primitive of the model. The above equation can be re-written as

$$
a_{i}=\frac{y_{i, t p s, 1997, m}}{x_{1997, m}}-\frac{\nu_{i, t p s, 1997, m}^{y}}{x_{1997, m}}
$$

which is simply the sum of two independent random variables with known distributions derived by dividing through by the known constant $x_{1997, m}: f_{1997, m}^{y \mid x_{1997, m}}$ and $f_{\nu^{y} \mid x_{1997, m}}$. The sum can therefore be expressed as a convolution of $\frac{y_{i, t p s, 1997, m}}{x_{1997, m}}$ and $-\frac{\nu_{i, t p s, 1997, m}^{y}}{x_{1997, m}}$

$$
f_{m}^{a}\left(a_{i}\right)=\int_{-\infty}^{\infty} f_{1997, m}^{y \mid x_{1997, m}}\left(a_{i}-\varepsilon\right) f_{\nu y \mid x_{1997, m}}(\varepsilon) d \varepsilon
$$

which is computable once I assume a distribution for $\nu^{y} \cdot{ }^{78}$ These non-parametric market ability distributions could then be recovered within the estimation algorithm that maximizes the likelihood over (in part) public school test score production function parameters.

\section{F Sample selection}

Tables 15 and 16 compare selected variables for the full sample and estimation samples. The means of most variables for public schools in the full and estimation samples are quite similar. In both the full and estimation samples, markets with charter schools have higher fractions of Black and Hispanic students, yet charter schools have lower fractions of both types of students relative to public schools in such markets. In both samples, female students comprise a smaller share of students at charter schools than they do for both types of public schools, and students attending charter schools are much more likely to have had at least one parent who has attended at least some college than students at either type of public school (in the estimation sample, $75 \%$ for charter schools versus $60 \%$ for public schools in markets with charters and $43 \%$ for public schools in markets without charters).

Table 17 shows that the sample restrictions do affect the test score distribution. In

\footnotetext{
${ }^{78} \mathrm{I}$ assume $\nu^{y}$ is normally distributed.
} 
Table 15: Summary Statistics for Full Sample

\begin{tabular}{|c|c|c|c|c|c|c|c|c|}
\hline & \multirow{2}{*}{\multicolumn{2}{|c|}{$\begin{array}{c}\text { All Markets } \\
\mathrm{N} \\
\mathrm{N}\end{array}$}} & \multicolumn{4}{|c|}{$\begin{array}{c}\text { Markets } \\
\text { with Charters }\end{array}$} & \multicolumn{2}{|c|}{$\begin{array}{c}\text { Markets } \\
\text { without Charters }\end{array}$} \\
\hline & & & Charter & $\mathrm{N}$ & Public & $\mathrm{N}$ & Public & N \\
\hline Markets $^{1}$ & \multirow{2}{*}{\multicolumn{2}{|c|}{1913}} & \multirow{2}{*}{\multicolumn{4}{|c|}{98}} & \multirow{2}{*}{\multicolumn{2}{|c|}{1785}} \\
\hline Ethnicity & & & & & & & & \\
\hline White & 63.45 & 644300 & 61.75 & 4689 & 53.52 & 38214 & 64.22 & 601396 \\
\hline Black & 29.44 & 298955 & 30.93 & 2349 & 37.89 & 27054 & 28.78 & 269552 \\
\hline Hispanic & 3.08 & 31274 & 1.25 & 95 & 4.31 & 3077 & 3 & 28103 \\
\hline Other & 4.03 & 40925 & 6.07 & 461 & 4.28 & 3056 & 4 & 37464 \\
\hline Female & 49.09 & 1015511 & 46.93 & 7594 & 49.53 & 71402 & 49.07 & 936515 \\
\hline \% Parent College & 47.92 & 1015365 & 70.11 & 7591 & 56.92 & 71373 & 47.06 & 936401 \\
\hline Grade & 6.97 & 1015511 & 6.81 & 7594 & 6.94 & 71402 & 6.97 & 936515 \\
\hline $\begin{array}{l}\text { \% Attending } \\
\text { Charter }\end{array}$ & 0.75 & 1015511 & 1 & 7594 & 0 & 71402 & 0 & 936515 \\
\hline $\begin{array}{l}\text { \% With Charter } \\
\text { in Market }\end{array}$ & 7.78 & 1015511 & 1 & 7594 & 1 & 71402 & 0 & 936515 \\
\hline
\end{tabular}

Table 16: Summary Statistics for Estimation Sample

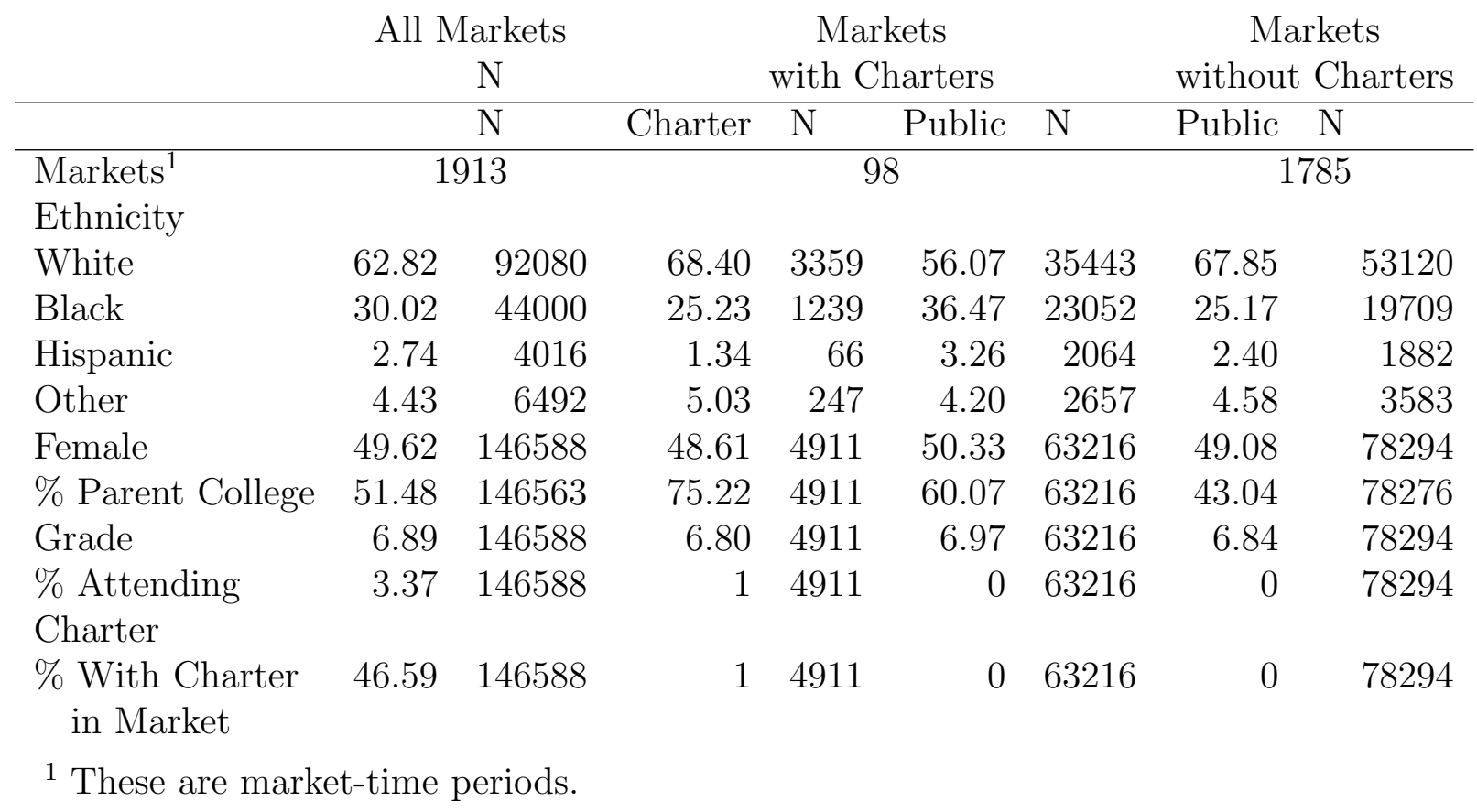


Table 17: Test Score Distribution for Full and Estimation Samples by Market and School Type

\begin{tabular}{lrlrlllr} 
& \multicolumn{3}{c}{ Full Sample } & \multicolumn{3}{c}{ Estimation Sample } \\
Entry & Mean & SD & \multicolumn{1}{c}{ N } & Mean & SD & \multicolumn{1}{c}{ N } \\
\hline Charter & 2.975 & 0.974 & 7376 & 3.1370 & 0.938 & 4941 \\
Public & 3.032 & 0.995 & 67219 & 3.0754 & 0.990 & 63216 \\
No Entry & & & & & & \\
\hline Public & 3.002 & 0.933 & 893413 & 3.0278 & 0.915 & 65085 \\
\hline
\end{tabular}

particular, removing students who attended a public school outside their market increases the average test score for students attending charter schools. ${ }^{79}$ About $20 \%$ of excluded students are from one charter school.

One concern with this restriction is that I am excluding charter school students who on average have lower test scores, which affects both mean ability of students at charter schools and school effort decisions. My estimation procedure may in effect be using an ability distribution of students that is different than that in the population. This does not in principle induce a bias in my estimates of test score production technologies at charter or public schools, because so long as I adequately control for student ability in the estimation of test score production functions those technology parameters will remain unbiased. School objective parameters may in principle be affected by the fact that I am removing attendant students from estimation and from the school decisions problems. This may not be a large effect, however, as charter schools have on average $18 \%$ of their students attending from outside their designated markets. Finally, note that the treatment effect of charters is positive so long as effective charter inputs are higher than effective monopoly inputs. ${ }^{80}$

So as long as I have correctly estimated school effort choices and effective school inputs to test score production, changes in the student ability distribution will change the scale of the direct TOT but not alter its direction, so long as mean ability for students attending charter schools is positive. If the treatment effect is positive, a lower mean of the charter school student ability distribution would only diminish the total treatment effect, resulting in upwards bias from excluding lower ability students. I solve for the direct treatment effect on excluded students attending charters by aggregating them into one synthetic market, recovering that

\footnotetext{
${ }^{79}$ Note that the extent of the bias induced by using a subset of charter school students cannot be derived from simple comparisons of the mean test scores of charter and public schools in entry markets. What matters is instead the ability distribution of excluded households.

${ }^{80}$ I define "effective inputs" as the expected test score at a school for student with ability 1, i.e. $\omega_{s}\left(\alpha_{s}\left(e_{s}^{o}\right)^{\beta_{s}}+\left(1-\alpha_{s}\right) k_{s}^{\beta_{s}}\right)^{\tau_{s} / \beta_{s}}$. Differences in student ability exacerbate differences in effective inputs between schools.
} 
market's ability distribution in a manner similar to Section 4.2.1, and computing treatment effects as I did in Section 6. The treatment effect on excluded students is $22 \%$ of a standard deviation in test scores, which brings the treatment effect over all charter school students down from $25 \%$ of a standard deviation to $23 \%$ of a standard deviation. ${ }^{81}$

${ }^{81}$ Details available from author upon request. 